\title{
1 Frugivory-related traits promote speciation of tropical palms
}

2

3

4 Renske E. Onstein ${ }^{1, *}$, William J. Baker ${ }^{2}$, Thomas L. P. Couvreur ${ }^{3}$, Søren Faurby ${ }^{4}$, Jens-Christian

5 Svenning ${ }^{5} \&$ W. Daniel Kissling ${ }^{1, *}$

6$$
8
$$

9

10 1

Total word count (Abstract, Introduction, Results, Discussion, Methods, References, and

21 Acknowledgements): 7300 words

22

Abstract (148 out of 150 words)

24 Main text (3137 out of 3500 words)

25 Introduction (812 words)

26 Methods: (2005 out of 3000 words)

27 References: 59 (excl. method references)

28

29 Number of figures: 4 (Figs. 1, 2, 3, 4 in colour)

30 Tables: 1

31 Supporting information: Yes 
34 Animal-mediated seed dispersal by frugivorous birds and mammals is central to the ecology and 35 functioning of tropical ecosystems, but whether and how frugivory-related traits have affected 36 plant speciation remains little explored. Fruit size is directly linked to plant dispersal capacity 37 and therefore influences gene flow and genetic divergence of plant populations. Using a global species-level phylogeny with comprehensive data on fruit sizes and plant species distributions we test whether fruit size has affected speciation rates of palms (Arecaceae), a characteristic tropical plant family. Globally, results reveal that palms with small fruit sizes have elevated speciation rates compared to those with large (megafauna) fruits. Speciation of small-fruited palms is particularly high in the understory of tropical rainforests in the New World, and on islands in the Old World. This suggests that frugivory-related traits in combination with 
The dispersal of seeds by fruit-eating animals such as birds and mammals is a key plant-animal interaction, especially in the tropics ${ }^{1,2}$. Frugivores constantly move around the seeds of animaldispersed plants and thereby affect dispersal, gene flow, and genetic structure of plant populations ${ }^{3}$. This ultimately can influence plant speciation ${ }^{2}$. Of particular importance for speciation are the frequencies of both restricted and long-distance dispersal because the degree of genetic divergence of plant populations depends on them ${ }^{2,4}$. To date, few case studies have examined the relationship between seed dispersal and speciation in animal-dispersed plants ${ }^{2,4}$, and large-scale studies testing the generality of this remain scarce.

Fruit size is a key trait in plant-frugivore interactions (Table 1). Fruit size sets a limit to the ingestion of fruits by relatively small-sized seed dispersers and therefore tends to be positively correlated with body sizes and gape widths of consumers ${ }^{5-8}$. Large fruits such as megafaunal fruits $(>4$ $\mathrm{cm}$ in size ${ }^{9,10}$ ) are predominantly dispersed by large-bodied, non-flying mammalian frugivores (e.g. elephants, a number of extinct proboscideans, tapirs, large primates, ground sloths) which have large home ranges ${ }^{11,12}$. This leads to frequent dispersal across large distances, high gene flow among plant populations and a low speciation probability ${ }^{2}$. In contrast, small fruits are predominantly dispersed by small- and medium-sized frugivores, including frugivorous birds, bats, scatter-hoarding rodents or other small-bodied non-flying mammals. Compared to mammalian megafauna, these frugivores generally have smaller home ranges and less frequent dispersal across large distances ${ }^{2}$, and island colonization is possible (e.g. via birds and bats) ${ }^{13}$. The more 'restricted dispersal' of non-megafaunal frugivores combined with occasional long-distance dispersal, e.g. as typically suggested from fattailed seed dispersal kernels ${ }^{3}$, can promote the divergence of isolated plant populations and hence increase the probability of speciation ${ }^{2}$. Consequently, a higher speciation rate can be predicted for plant lineages with small fruits compared to those with large, megafaunal fruits ('fruit-size hypothesis', H1 in Table 1).

Beyond fruit size, plants with animal-dispersed fruits in the understory of tropical rainforests have been associated with high speciation rates ${ }^{4}$, especially when compared to taller plant growth forms (e.g. canopy trees) (Table 1). This could be caused by the sedentary nature of small- and medium-sized seed dispersers in the forest understory because their spatially restricted dispersal will result in low gene flow among plant populations ${ }^{14,15}$ and thus a higher probability of allopatric plant speciation ${ }^{4}$. Animal-dispersed understory plants should therefore diversify more extensively than other plants ${ }^{4}$, especially in regions where small-bodied understory birds are abundant and species-rich ${ }^{16}$. This predicts a higher speciation rate of understory lineages compared to other growth forms ('understory habitat hypothesis', H2 in Table 1). Only few studies have tested the understory habitat hypothesis ${ }^{4,17}$ and it remains unclear how general and widely applicable it is across taxa and regions. Oceanic barriers make seed dispersal to islands challenging. The isolation of islands can restrict colonization and limit gene flow among plant populations (Table 1). Long-distance dispersal of animal-dispersed plants to remote oceanic islands usually depends on frugivores that are strong fliers 
and hence able to cross large stretches of open water, including birds such as hornbills, macaws and fruit pigeons, and volant mammals such as fruit bats ${ }^{13,18}$. Seed dispersal to remote islands is therefore generally rare, leading to increased possibilities for genetic differentiation by isolation and allopatric plant speciation ('island colonization hypothesis', H3 in Table 1). Especially on islands that have been isolated for millions of years (i.e. volcanic islands or atolls), plant speciation rates can be expected to be higher compared to the mainland or continental islands because the latter have experienced more connectivity (and hence gene flow) through geological time. Although adaptive radiations on islands have been studied extensively ${ }^{19}$, tests of the island colonization hypothesis for animal-dispersed plant taxa remain sparse.

Here, we quantify speciation rates in relation to fruit size, understory habitat and island colonization in palms (Arecaceae), a species-rich animal-dispersed plant family typical for tropical rainforests ${ }^{20,21}$. Among angiosperm families, the palm family is one of the major food plant groups for vertebrate frugivores in the tropics ${ }^{2}$ and a large number of both avian and mammalian frugivores have been observed to feed on them ${ }^{22}$. Together with data on fruit sizes, growth forms and species distributions we estimate speciation rates from a species-level phylogeny of the palm family ${ }^{23}$ globally as well as separately for the New World (including South, Central and North America and the Caribbean) and the Old World (including Australia, Indomalaya, Oceania, Pacific, Africa, Madagascar and surrounding islands) $)^{24}$. More specifically, we tested the following three hypotheses (Table 1): (H1) palms with small fruit sizes $(<4 \mathrm{~cm})$ have higher speciation rates than palms with large fruit sizes (i.e. megafaunal fruits $\geq 4 \mathrm{~cm}$ ) ('fruit size hypothesis'); (H2) understory palms (especially those with small fruits) show higher speciation rates than canopy palms ('understory habitat hypothesis'); and (H3) dispersal to oceanic islands has increased speciation rates compared to speciation on the mainland and continental islands ('island colonization hypothesis').

\section{Results}

The majority of palms have relatively small fruits ( $<4 \mathrm{~cm}$ in length; $n=1607$ species), but about $12 \%$ of all sampled palm species have large, megafauna fruits ( $\geq 4 \mathrm{~cm}$ in length; $n=229$ species) (Fig. 1).

Overall, fruit sizes of animal-dispersed palms vary widely from small $0.4-0.5 \mathrm{~cm}$ fruits in some Areca, Bactris, Calamus, Chamaedorea, Coccothrinax, Dypsis, Geonoma, Licuala and Pinanga species to large $>10 \mathrm{~cm}$ fruits in genera such as Borassus, Metroxylon and Phytelephas (Supplementary Table 1). Some palm species with particularly large fruits such as the coconut (Cocos nucifera, $22.5 \mathrm{~cm}$ fruit size), the nipa palm (Nypa fruticans, $11.5 \mathrm{~cm}$ fruit size) and the double coconut (Lodoicea maldivica, $45 \mathrm{~cm}$ fruit size) are not dispersed by animals (Supplementary Table 1). Apart from these few exceptions, all other palm species have vertebrate-dispersed fruit types (drupes and berries) and both birds and mammals are their main seed dispersers ${ }^{22}$. 
118 Fruit size-dependent speciation. Using information on fruit sizes of 1836 palm species together with

119 the Binary State Speciation and Extinction (BiSSE) model $^{25,26}$ we tested whether small fruits are

120 associated with high speciation rates (H1, Table 1). The best fitting BiSSE model showed that

121 speciation rates of small-fruited palm lineages are higher than those of large-fruited palm lineages

122 (H1; Fig. 2). This supported the fruit size hypothesis both globally (Fig. 2a) and in the Old World (Fig.

123 2c), but interestingly not in the New World (Fig. 2b). The global BiSSE model indicated that small-

124 fruited palms have a 1.6-fold higher speciation rate than large-fruited palms (median $\lambda_{\text {small }}=0.22, \lambda_{\text {large }}$

$125=0.14$ ). A 3.4-fold increase in speciation rate due to small fruit sizes was inferred for the Old World

126 (median $\lambda_{\text {small }}=0.48, \lambda_{\text {large }}=0.13$ ). A potential confounding factor between speciation rate and fruit

127 size could be the allometric relationship between fruit size and overall plant size (Supplementary Fig.

128 1). Using data on palm stem heights as a measure of overall plant size showed that the high speciation

129 rate of small-fruited palm lineages persisted when overall plant size was accounted for (for details see

130 Supplementary Note 1). Hence, there was strong evidence for the hypothesized increase of speciation

131 rates in small-fruited vertebrate-dispersed palm clades relative to large, megafaunal-fruited palms, at

132 least for the Old World.

133

134 Understory habitat. About $39 \%$ of all sampled palm species ( $n=802$ species) occur in the forest

135 understory, and palms with small fruits are more common in the understory than palms with large

136 fruits (91\% and $9 \%$, respectively). In general, understory palms also have smaller fruits than canopy

137 palms ( median $_{\text {understory }}=1.25 \mathrm{~cm}$ vs. median $_{\text {canopy }}=1.7 \mathrm{~cm}$, Supplementary Fig. 2). To quantify the

138 relative importance of fruit size and understory habitat for speciation rates in palms, we used fruit

139 sizes and additional data on understory habitat in a Multiple State Speciation and Extinction model

140 (MuSSE multistate) ${ }^{27}$ to test the understory habitat hypothesis (H2, Table 1). We compared the

141 additive and interaction effects of these two binary traits (small fruits and understory habitat) to a

142 baseline MuSSE model that estimated speciation rates when both traits were absent, i.e. relative to

143 palm lineages that have large fruits and a canopy habit. Globally, the best-fitting MuSSE model

144 indicated that both small fruits and understory habitat had a positive effect on speciation rates relative

145 to the baseline (H2; Fig. 3a, compare yellow vs. grey box-and-whisker plots). In addition, there was a

146 positive interaction effect (red box-and-whisker plot, Fig. 3a), indicating that fruit size and understory

147 habitat acted synergistically to increase speciation rates. Hence, understory palms with small fruits had

148 the highest speciation rates at a global scale. Since understory palm species are more common in the

149 New World than the Old World relative to canopy species ( $45 \%$ and $36 \%$, respectively), we further

150 tested whether this interaction effect differed among these regions. In the New World, the best-fitting

151 MuSSE model confirmed the global analysis, i.e. both additive and interactive effects of small fruit

152 size and understory habitat were detected (Fig. 3b). However, in the Old World only positive additive

153 effects were supported, but no interaction term (Fig. 3c). 
155 Island colonization. About $13 \%$ of all included palm species ( $n=331$ species) are restricted in their

156 occurrence to oceanic islands, $80 \%$ are restricted to the mainland or to continental islands $(n=2036$

157 species), and 7\% occur both on oceanic islands and mainland or continental islands ( $n=190$ species).

158 Oceanic island-distributed palms have on average slightly larger fruits than palms that are distributed

159 on mainland or continental islands $\left(\right.$ median $_{\text {island }}=1.6 \mathrm{~cm}$ vs. median $_{\text {mainland }}=1.5 \mathrm{~cm}$, Supplementary

160 Fig. 2). Using MuSSE models, we tested whether small fruit size in combination with oceanic island

161 colonization has an effect on speciation rates (H3, Table 1). At a global scale, the best-fitting MuSSE

162 model for fruit size and island colonization indicated that small fruits and island colonization have

163 both positive additive effects (Fig. 4a, compare yellow vs. grey box-and-whisker plots) as well as

164 positive interactive effects (red box-and-whisker plot, Fig. 4a), compared to large-fruited mainland-

165 distributed palm lineages. Interestingly, in the New World the best-fitting MuSSE model only

166 supported positive additive effects of small fruit size and island colonization, but no interaction effect

167 (Fig. 4b). Moreover, the posterior distributions of the speciation rates resulting from the Bayesian

168 analysis strongly overlapped, suggesting only a slight increase in speciation rates due to small fruits

169 and island colonization relative to large-fruited mainland palms (Fig. 4b). However, in the Old World

170 the results from the global analysis were confirmed (Fig. 4c), suggesting that small-fruited palm

171 lineages on oceanic islands have particularly high speciation rates.

\section{Discussion}

174 Using trait-dependent diversification models and time-calibrated species-level phylogenies of palms

175 we show that dispersal-relevant traits are important drivers of palm radiations. Speciation rates were

176 higher for palm lineages with small fruits ( $<4 \mathrm{~cm}$ in length) compared to large-fruited, megafauna-

177 adapted lineages ( $\geq 4 \mathrm{~cm}$ in length), especially in the understory of New World tropical forests as well

178 as on Old World oceanic islands. These results suggest that plant speciation is enhanced by the

179 evolution of small fruit sizes in conjunction with understory habitat and island colonization. This

180 directly relates to the dispersal and movement behaviour of particular frugivores, e.g. the spatially-

181 restricted seed dispersal of small-bodied frugivores in the understory of rainforests or the seed

182 dispersal to isolated islands by strong-flying frugivores that can cross oceanic barriers. These results

183 suggest that frugivory-related traits are important drivers of speciation in vertebrate-dispersed tropical

184 plants, and hence provide trait-based insights into how frugivory might influence biodiversity in the

185 tropics $^{28}$.

187 Fruit size-dependent speciation. We hypothesized that speciation of small-fruited palms is higher

188 than speciation of large-fruited palms (H1, Table 1). This was supported by our results in the global

189 and Old World analyses (Fig. 2). In general, vertebrate-dispersed plants with small fruit sizes tend to

190 be dispersed more frequently by small-bodied frugivores than by large-bodied frugivores ${ }^{6-8}$. Since

191 vertebrate body size scales with home range area, small-bodied frugivores on average have a more 
192 restricted space use than large-bodied frugivores ${ }^{11,12,29}$. As a consequence, small-fruited plants

193 typically show frequent short-distance and rare long-distance dispersal events ${ }^{3,30}$. Large-bodied

194 frugivores often show large-scale movements ${ }^{18,31}$, which increases the frequency of long-distance

195 dispersal events, particularly in large-fruited plants ${ }^{2}$. Dispersal distances of small-fruited vertebrate-

196 dispersed plants therefore tend to be shorter than those of large-fruited plants, which results in lower

197 gene flow among plant populations and therefore an increased probability of genetic differentiation

198 and allopatric speciation ${ }^{2}$. Biogeographic comparisons of fruit sizes ${ }^{5}$ and studies of disperser loss in

199 tropical forest fragments ${ }^{32}$ also support the idea that seed disperser body size imposes a strong

200 selective pressure on fruit size. Our results provide macroevolutionary evidence that fruit size can have

201 a strong influence on diversification dynamics of vertebrate-dispersed plants.

203 Understory habitat. Some vertebrate-dispersed plant clades are particularly species-rich in the

204 understory of tropical rainforests ${ }^{4,17}$. This has been used to hypothesize that understory habitat

205 generally promotes plant speciation in the tropics (H2, Table 1). Our results (Fig. 3) show that small

206 fruit size in combination with understory habitat leads to exceptionally high speciation rates in palms,

207 but only in the New World and not in the Old World. Indeed, several Neotropical understory palm

208 genera with small fruits (e.g. Chamaedorea and Geonoma) have been mentioned in support of the

209 understory habitat hypothesis ${ }^{4}$. These genera along with some other palm genera (i.e. the node leading

210 to Desmoncus, Bactris and Astrocaryum) represent a diversification rate shift across the palm

211 phylogenetic tree ${ }^{33}$. Radiations of these palm genera could be, at least partly, driven by the spatially-

212 restricted movements of the many small-bodied understory frugivores in Neotropical forests ${ }^{4,16}$. For

213 instance, many Neotropical understory birds show higher genetic differentiation than canopy birds,

214 indicating low dispersal across biogeographic barriers such as rivers ${ }^{14,34}$. This limited dispersal of

215 understory frugivores reduces gene flow and ultimately promotes speciation ${ }^{2,15}$. In the Old World,

216 speciation rates of understory palms were also higher than those of large-fruited canopy palms, but no

217 additional increase in speciation rates due to small fruit sizes was supported. This may be explained by

218 the paucity of small-bodied, sedentary understory frugivores in the Old World ${ }^{16,35}$ and radiations of

219 large-bodied, ground-living avian frugivores comparable to, for example, the New World cracids

220 (Cracideae) and trumpeters (Psophiidae), are relatively rare in the Old World ${ }^{35,36}$. Furthermore, these

221 results conform to the (relative) scarcity of Old World understory palms at present (36\% vs. $45 \%$ in

222 the Old World and New World, respectively). Beyond frugivory, differences in speciation of small-

223 fruited understory palms between the New World and the Old World may also be explained by the

224 taller status of the Old World rainforests ${ }^{37}$, potentially due to competition-driven selection for larger

225 growth forms, or due to historical climate stresses, notably in Africa ${ }^{38}$.

227 Island colonization. Many islands show spectacular palm radiations ${ }^{38-41}$, suggesting that island

228 colonization could be a major driver of palm speciation. Oceanic islands and island-like environments 
are characterized by restricted colonization and limited gene flow ${ }^{4,42-45}$ that can increase speciation rates relative to the mainland or continental islands (H3, Table 1). Our results (Fig. 4) supported this hypothesis by demonstrating a particularly high speciation rate for small-fruited palm lineages on Old

232 World islands. This result is primarily driven by palm diversification in Southeast Asia (95\% of the

233 Old World palm species occur in Indomalaya, Australasia, Pacific and the Western Indian Ocean)

234 rather than diversification on the relatively species-poor African continent. This was supported by a similar result when removing the Afrotropical species $(n=56)$ from the analysis (results not shown).

236 The high diversity of palms on Old World islands ${ }^{39,46}$ coincides with a high species richness of large-

237 bodied, strong-flying avian frugivores in this region, especially the predominance of fruit pigeons 238 (Columbidae) in Australasia and frugivorous hornbills (Bucerotidae) in Indomalaya ${ }^{1}$. These birds ${ }^{42}$ as 239 well as fruit bats (Pteropodidae) ${ }^{13}$ successfully colonize remote islands and thereby contribute to long240 distance seed dispersal of vertebrate-dispersed plants across oceanic barriers. Further empirical studies 241 provide evidence of frequent long-distance seed dispersal of large-bodied birds at landscape and 242 biogeographic scales ${ }^{18,31,47}$ as well as of dispersal of palm fruits to remote islands ${ }^{22,48}$. Hence, the 243 diversity of these frugivorous birds may have facilitated island colonisation by palm lineages with 244 relatively small fruit sizes (i.e. $<4 \mathrm{~cm}$, small enough to be swallowed by ocean-crossing frugivorous 245 birds and bats) in the Old World. The lack of a relationship between speciation rates, fruit size and 246 island colonization in the New World may be due to fewer oceanic islands in this part of the world, 247 congruent with the occurrence of relatively few island-distributed palm species in the New World 248 compared to the Old World (8\% vs. $28 \%$ in the New World and Old World, respectively).

249 Furthermore, many bird families that are widespread in Neotropical rainforests often lack 250 representative species on oceanic islands ${ }^{34}$, which may have constrained the overall dispersal and 251 subsequent radiation of Neotropical palms on oceanic islands.

253 Other potential drivers of palm radiations. Remarkable evolutionary radiations and exceptionally 254 high diversification rates have been previously identified for various palm genera (e.g. ${ }^{20,33,38}$ ). Such 255 fast diversification might not only be driven by interactions with frugivorous vertebrates, but also by 256 heterogeneity in topography, soils and microenvironments ${ }^{49-51}$, long-term climate and biome 257 stability $^{38}$, or other types of biotic interactions such as those with herbivores and pathogens ${ }^{52}$. A 258 potentially confounding factor in terms of correlated evolution between fruit size and plant size ${ }^{53}$ was 259 not supported in our analyses because the negative association between fruit size and speciation 260 remained after correcting for plant height (see Supplementary Note 1). Beyond fruit sizes, other fruit traits (e.g. fruit colour, softness, odour, and exposure) or defence traits (e.g. spines) could also 262 influence the diversification of vertebrate-dispersed plants ${ }^{54-56}$. Moreover, the former presence of a 263 rich, now largely extinct megafauna (e.g. extinct proboscideans, pilosans, cingulates and 264 notoungulates) in the Neotropics would have influenced long-distance seed dispersal and gene flow of 
265 large-fruited palms ${ }^{9,10}$, and may explain some of the observed differences in diversification between

266 New World and Old World megafauna-fruited palms (Figs 2-4 and Supplementary Fig. 4).

\section{Conclusions}

268 Although several lines of evidence have previously been used to infer a potential role of frugivores in 269 the diversification of vertebrate-dispersed plants (e.g. ${ }^{2,4,17,57}$ ), rigorous quantitative tests of specific 270 hypotheses in a phylogenetic framework have been limited, especially beyond sister clade 271 comparisons ${ }^{2}$. Using a species-level phylogeny of palms combined with extensive trait datasets, we 272 demonstrated that speciation rates of palms are highest in small-fruited palm lineages $(<4 \mathrm{~cm}$ fruit 273 size), especially in the understory of New World rainforests as well as in insular environments of

274 Southeast Asia and the Pacific. In both systems, comparably small fruits probably promote the

275 establishment of isolated populations through their interaction with particular frugivores. Considering

276 the evolution of intrinsic traits (e.g. fruit size, growth form) in interaction with geography (e.g. oceanic

277 islands) and the biotic environment (e.g. frugivores and their movement behaviours) is therefore

278 essential for understanding plant radiations ${ }^{58,59}$. The combination of time-calibrated phylogenies with

279 ecological, interaction-relevant traits is thus particularly useful for gaining a deeper understanding of

280 how biotic interactions have constrained or mediated the evolutionary radiations of tropical plants.

\section{Methods}

283 Phylogeny. We used an all-evidence species-level supertree of palms which includes almost all 284 accepted palm species $(n=2539)^{23}$. This time-calibrated, phylogenetic tree is based on a backbone 285 generated from nine plastid and four nuclear markers as well as morphological data ${ }^{60}$, and additional 286 molecular and morphological data for several genera ${ }^{23}$. The phylogenetic tree was dated using five 287 calibration points ${ }^{21}$. A Bayesian modeling approach was used to place species without genetic or morphological data in the phylogeny, based on taxonomy (for details see ref. ${ }^{23}$ ). As this leads to uncertainty in the exact placement of a species within the phylogeny, all analyses were performed on a set of 100 randomly sampled palm phylogenetic trees available from ref. ${ }^{23}$.

Data on fruit sizes. Information on fruit sizes was collected for a total of 1836 palm species (ca. $70 \%$ of all palm species) from various sources, including primary literature, monographs, herbaria and palm websites (all sources are listed in Supplementary data sources). Specifically, we calculated the average fruit length for each species (based on multiple records per species if available), because fruit length is the most commonly reported fruit size trait in monographs and species descriptions. For the analyses, we classified species into two groups: small-fruited palms (fruits $<4 \mathrm{~cm}$ in length) and large-fruited palms (fruits $\geq 4 \mathrm{~cm}$ in length). Since palm fruits are usually single-seeded ${ }^{20}$, the large-fruited palms represent species with 'megafaunal' fruits ${ }^{9,10}$. Across the palm family, at least 229 palm species have 
megafaunal fruits (Fig. 1), and about one third of the palm genera have at least one species with such fruits (Supplementary Table 1). We used the binary state of fruit size (small/large) rather than a continuous variable because the implemented diversification models (see below) deal with binary data, and because species with large, megafaunal fruit sizes are dependent on seed dispersal by large-bodied mammalian frugivores (megafauna), thereby excluding volant frugivores (birds, bats) and small- and medium-sized frugivores. In contrast, species with small fruit sizes are predominantly ingested by birds and small- and medium-sized mammalian seed dispersers ${ }^{2}$.

Data on understory habitat. To quantify affiliation with the forest understory, we compiled specieslevel data on maximum stem height for 2073 palm species (ca. $81 \%$ of all palm species) from the same sources as used for the fruit size data (see Supplementary data sources). For all palm species, we additionally determined their main growth form (climber, acaulescence, erect shrub/tree). From these data, we estimated whether palms present their fruits in the understory. This included short-stemmed palms (maximum stem height $\leq 5 \mathrm{~m}$ ) as well as all acaulescent species (i.e. having no or only a very short stem concealed in the ground). Palms with a stem height $>5 \mathrm{~m}$ were considered to be nonunderstory plants, i.e. tall-stemmed or medium-sized palms and most climbers (referred to as 'canopy').

Data on island colonization. The palm family has a pantropical distribution (i.e. it occurs in all tropical regions). To quantify species distributions on islands, we compiled global presence-absence data for all palm species from the world checklist of palms ${ }^{61}$. This exhaustive, authoritative checklist records palm species occurrence within level 3 geographic units as defined by the International Working Group on Taxonomic Databases (TDWG) (referred to as 'botanical countries') ${ }^{61}$. These generally correspond to countries although larger countries such as the United States are normally broken down into smaller political units. Palm occurrence data are freely available from the continuously updated World Checklist of Monocotyledons (http://apps.kew.org/wcsp), and we here used a database version downloaded on July 2015. For our analyses, we defined a binary state

326 (island/mainland) describing whether a species occurs on volcanic and atoll islands (referred to as

327 'island'), or on the mainland or on continental islands (referred to as 'mainland'), following the 328 classification from ref ${ }^{62}$. This classification follows geology as a surrogate for isolation, in which oceanic and atoll islands have arisen as newly formed land, whereas continental islands are either part of the continental shelf or were once connected to continental landmasses (e.g. Madagascar). The occurrence of palm species on oceanic and atoll islands consequently must have resulted from colonization and speciation in isolation, whereas palm lineages on continental islands have experienced less isolation. This classification closely matches the classification based on the connectivity of islands to the mainland during the last glacial maximum, as quantified by ref. ${ }^{63}$. 
336 Performance of trait-based models. In this study, we tested the impact of specific traits on the

337 diversification of lineages using the maximum likelihood based 'state speciation and extinction' or

338 'SSE' models ${ }^{25,26}$. These methods calculate the probability that a lineage evolved as observed given a

339 model of character evolution. However, SSE models have recently been criticized for high type I error

340 rates $^{64}$, suggesting that a significant effect of a trait on speciation rates can be detected even if it is not

341 truly present. We evaluated this bias by performing simulations in which neutral binary traits evolved

342 on 100 empirical palm phylogenies ${ }^{23}$ under several transition rate scenarios, as recommended by ref. ${ }^{64}$.

343 These simulated (neutral) binary traits are expected to be neutral with respect to speciation

344 rates. We evaluated the Bayesian credible intervals in speciation rates between these simulated binary

345 traits after running a Bayesian Markov Chain Monte Carlo (MCMC) for 10,000 generations on the 100

346 palm phylogenies. Our results showed a strong overlap of Bayesian credible intervals between

347 character states on speciation rates under all transition rate scenarios (Supplementary Fig. 3),

348 supporting the expectation that these neutral traits do not affect speciation rates in palms. This

349 suggests that the empirical results can be reliably obtained from the 'SSE' models. In addition, our

350 dataset meets the other requirements for applying 'SSE' models, such as sufficient replication events

351 (e.g. the independent evolution of small fruit sizes) ${ }^{65},>300$ species and balanced character state

352 distributions ${ }^{66}$ (for more details on these simulations see Supplementary Note 2).

354 Fruit size-dependent speciation. We used the Binary State Speciation and Extinction (BiSSE)

355 model ${ }^{25,26}$ implemented in the 'diversitree' package ${ }^{27}$ in $\mathrm{R}^{67}$ to model speciation (' $\lambda$ '), extinction (' $\mu$ ')

356 and transition (' $q$ ') rates of small-fruited vs. large-fruited palm lineages (H1 in Table 1). The BiSSE

357 model jointly estimates speciation, extinction and transition rates of a binary trait by using dated

358 phylogenetic trees, and trait states assigned to the species at the tips of the trees. We focus on

359 speciation rates because our hypotheses (Table 1) directly refer to speciation rather than extinction or

360 net diversification. Nevertheless, the joint-estimation of these rates is desirable as trait changes may

361 not be independent from speciation and extinction rates ${ }^{26}$. We report and discuss all evolutionary rates

362 other than speciation in Supplementary Note 3 and Supplementary Fig. 4, and provide an overview of

363 the model selection globally as well as for the New World and Old World, respectively

364 (Supplementary Tables 2-4). We fitted eight BiSSE models with decreasing complexity (parameters)

365 and selected the best-fitting models based on likelihood-ratio tests under a Chi-square distribution and

366 the Akaike Information Criterion (AIC) (Supplementary Tables 2-4). These models included

367 constraints on speciation, extinction and transition rates between trait states ${ }^{25}$. Maximum likelihood

368 was used to optimize full and constrained models. BiSSE enables correcting for species and their traits

369 not sampled in the datasets by indicating a sampling fraction, i.e. $32 \%$ of small-fruited and $18 \%$ of

370 large-fruited palm species were not sampled in the global dataset. This fraction was based on imputed

371 trait values from the PhyloPars algorithm ${ }^{68}$ for those species sampled in the phylogenetic tree but

372 lacking fruit size data (these imputed trait values were only used to calculate sampling fractions, not in 
the actual analyses). A MCMC was run for the best-fitting model for 10,000 generations on 100 randomly sampled palm phylogenies. We evaluated the posterior distribution of these Bayesian rates, and in case the $95 \%$ Bayesian credibility intervals between parameter states did not overlap, we considered them significantly different from each other ${ }^{25}$.

All analyses were run globally as well as separately for the New World (including South, Central and North America as well as the Caribbean) and the Old World (including Australia, Indomalaya, Oceania, Pacific, Africa, Madagascar and surrounding islands). This geographic division was used because most palm species (as well as genera) are endemic to one of these regions ${ }^{38}$. Hence, these regions are characterized by distinct historical differences in terms of palm diversification ${ }^{33,69}$, frugivore communities ${ }^{1}$, and representation of understory palm species ( $45 \%$ and $36 \%$ in the New World and Old World, respectively) and island-distributed palm species ( $8 \%$ and $28 \%$ in the New World and in the Old World, respectively).

As results may be biased by the allometric relationship between fruit size and plant size, we repeated the analyses after accounting for the correlation between palm maximum stem heights and fruit sizes. The effect of residual fruit sizes (after correcting for maximum plant height) on speciation rates was assessed with BiSSE (for details on the approach see Supplementary Note 1, for model selection see Supplementary Table 5 and for results see Supplementary Figs. 1 and 4). However, as these residuals do not represent 'true' small and large fruits, we also investigated the effect of residual fruit sizes on speciation rates using the Quantatative Speciation and Extinction model (QuaSSE) ${ }^{70}$. QuaSSE can be used to test the effect of a continuous trait on speciation rates by testing the fit of models describing the distribution of the response (i.e. speciation rate) to the trait (e.g. constant, linear or sigmoidal). Details on the methods and results of this analysis are provided in Supplementary Note 1, Supplementarty Table 6 and Supplementary Fig. 5.

Furthermore, to test whether our binary classification of fruit size biased the results, we additionally tested the effect of fruit size as a continuous trait on speciation rates. We first estimated speciation rate heterogeneity across the phylogeny with a Bayesian Analysis of Macroevolutionary Mixtures (BAMM) ${ }^{71}$ and then compared the observed difference in speciation rate between palms that exhibit different fruit sizes to a background speciation rate through randomizing the estimated tip speciation rates from the BAMM outputs. These additional analyses also confirmed the high speciation rate of small-fruited palm lineages. Details on the methods and results of this analysis are provided in the Supplementary Note 4 and Supplementary Fig. 6.

Speciation rates due to understory habitat and island colonization. The effects of a trait (e.g. fruit size) on speciation rates may be enhanced by an interaction effect with another trait. For example, palms in the understory or on islands may have particularly high speciation rates if they have also small fruits. To disentangle such effects we implemented the Multiple State Speciation and Extinction model (MuSSE multistate) ${ }^{27}$. The MuSSE model can be used to quantify the additive and interactive 
410 effects of two binary traits (e.g. small fruit size and understory growth form, or small fruit size and 411 island colonization) on speciation, extinction and transition rates. The model intercept of the MuSSE

412 model (the 'base model') estimates speciation rates when both traits are absent (e.g. palm lineages

413 with large fruits that do not grow in the understory). The interaction term (when both traits are present)

414 will indicate whether these traits may interact in either a positive way (i.e. both traits increase

415 speciation rates) or a negative way (i.e. both traits decrease speciation rates).

416 To quantify trait-dependent diversification for both binary trait combinations (H2: small/large

417 fruit size and understory/canopy habitat; H3: small/large fruit size and island/mainland distribution),

418 we compared the likelihood of a total of sixteen models with increasing complexity (Supplementary

419 Table 7). We used stepwise AIC model selection, globally as well as separately for the New World

420 and Old World, and selected the models with the lowest AIC (Supplementary Tables 8-9). A MCMC

421 for the best-fitting model (based on AIC) was run for 10,000 generations on 100 palm phylogenies.

422 We tested for the additive and interactive effects of small fruits and understory habitat (compared to

423 large-fruited canopy palms) on speciation rates (Supplementary Table 8), and between small fruits and

424 oceanic island colonization (compared to large-fruited mainland/continental island-distributed palms)

425 on speciation rates (Supplementary Table 9). We report and discuss all evolutionary rates other than

426 speciation rates in Supplementary Note 5 and Supplementary Fig. 7.

428 Data availability. The phylogenetic data that support the findings of this study are available from

429 ref. $^{23}$. The palm species distribution data are available from the World Checklist of Selected Plant

430 Families (http://apps.kew.org/wcsp). All scripts to perform the analyses in this study are available

431 upon request from the first author [REO]. The palm trait data that support the findings of this study are

432 available upon request from the last author [WDK]. 


\section{References}

4351 Kissling, W. D., Böhning-Gaese, K. \& Jetz, W. The global distribution of frugivory in birds. Global Ecology and Biogeography 18, 150-162, doi:10.1111/j.1466-8238.2008.00431.x (2009). Fleming, T. H. \& Kress, W. J. The ornaments of life: coevolution and conservation in the tropics. (Chicago University Press, 2013).

3 Nathan, R. \& Muller-Landau, H. C. Spatial patterns of seed dispersal, their determinants and consequences for recruitment. Trends in Ecology \& Evolution 15, 278-285, doi:http://dx.doi.org/10.1016/S0169-5347(00)01874-7 (2000). Givnish, T. J. Ecology of plant speciation. Taxon 59, 1326-1366 (2010). Lord, J. M. Frugivore gape size and the evolution of fruit size and shape in southern hemisphere floras. Austral Ecology 29, 430-436 (2004). Wheelwright, N. T. Fruit-Size, gape width, and the diets of fruit-eating birds. Ecology 66, 808-818, doi:10.2307/1940542 (1985). Jordano, P. in Seeds: the ecology of regeneration in plant communities 2 125-166 (2000). Herrera, C. M. in Plant-animal interactions: an evolutionary approach (eds Carlos M. Herrera \& Olle Pellmyr) 185-208 (John Wiley \& Sons, 2002). Guimarães, P. R., Jr., Galetti, M. \& Jordano, P. Seed dispersal anachronisms: rethinking the fruits extinct megafauna ate. PLOS ONE 3, e1745, doi:10.1371/journal.pone.0001745 (2008). fruits the gomphotheres ate. Science 215, 19-27, doi:10.1126/science.215.4528.19 (1982).

12 Milton, K. \& May, M. L. Body weight, diet and home range area in primates. Nature 259, relationships for mammal and bird home ranges. Nature 418, 527-530 (2002).

13 Shanahan, M., Harrison, R. D., Yamuna, R., Boen, W. \& Thornton, I. W. B. Colonization of an island volcano, Long Island, Papua New Guinea, and an emergent island, Motmot, in its caldera lake. V. colonization by figs (Ficus spp.), their dispersers and pollinators. Journal of Biogeography 28, 1365-1377 (2001).

14 Burney, C. W. \& Brumfield, R. T. Ecology predicts levels of genetic differentiation in neotropical birds. The American Naturalist 174, 358-368, doi:10.1086/603613 (2009).

15 Salisbury, C. L., Seddon, N., Cooney, C. R. \& Tobias, J. A. The latitudinal gradient in dispersal constraints: ecological specialisation drives diversification in tropical birds. Ecology Letters 15, 847-855, doi:10.1111/j.1461-0248.2012.01806.x (2012).

16 Karr, J. R. Geographical variation in the avifaunas of tropical forest undergrowth. The Auk $\mathbf{9 7}$, 283-298 (1980).

17 Smith, J. F. High species diversity in fleshy-fruited tropical understory plants. The American Naturalist 157, 646-653, doi:10.1086/320625 (2001).

18 Holbrook, K. M., Smith, T. B. \& Hardesty, B. D. Implications of long-distance movements of frugivorous rain forest hornbills. Ecography 25, 745-749, doi:10.1034/j.16000587.2002.250610.x (2002).

19 Losos, J. B. \& Ricklefs, R. E. Adaptation and diversification on islands. Nature 457, 830-836 (2009).

20 Dransfield, J. et al. Genera Palmarum: The evolution and classification of palms. (Kew Publishing, 2008).

21 Couvreur, T. L. P., Forest, F. \& Baker, W. J. Origin and global diversification patterns of tropical rain forests: inferences from a complete genus-level phylogeny of palms. $B M C$ Biology 9, 1-12, doi:10.1186/1741-7007-9-44 (2011).

22 Zona, S. \& Henderson, A. A review of animal-mediated seed dispersal of palms. Selbyana 11, 6-21 (1989).

23 Faurby, S., Eiserhardt, W. L., Baker, W. J. \& Svenning, J.-C. An all-evidence species-level supertree for the palms (Arecaceae). Molecular Phylogenetics and Evolution 100, 57-69, 
24 Brummitt, R. K., Pando, F., Hollis, S. \& Brummitt, N. World geographical scheme for recording plant distributions. (International Working Group on Taxonomic Databases for Plant Sciences (TDWG), 2001).

25 FitzJohn, R. G., Maddison, W. P. \& Otto, S. P. Estimating trait-dependent speciation and extinction rates from incompletely resolved phylogenies. Systematic Biology 58, 595-611, doi:10.1093/sysbio/syp067 (2009).

26 Maddison, W. P., Midford, P. E. \& Otto, S. P. Estimating a binary character's effect on speciation and extinction. Systematic Biology 56, 701-710, doi:10.1080/10635150701607033 (2007).

27 FitzJohn, R. G. Diversitree: comparative phylogenetic analyses of diversification in R. Methods in Ecology and Evolution 3, 1084-1092, doi:10.1111/j.2041-210X.2012.00234.x (2012).

28 Richardson, J. E. \& Pennington, R. T. Editorial: Origin of tropical diversity: from clades to communities. Frontiers in Genetics 7, doi:10.3389/fgene.2016.00186 (2016).

29 Jetz, W., Carbone, C., Fulford, J. \& Brown, J. H. The scaling of animal space use. Science 306, 266-268, doi:10.1126/science.1102138 (2004).

30 Jordano, P., García, C., Godoy, J. A. \& García-Castaño, J. L. Differential contribution of frugivores to complex seed dispersal patterns. Proceedings of the National Academy of Sciences 104, 3278-3282, doi:10.1073/pnas.0606793104 (2007).

31 Lenz, J. et al. Seed-dispersal distributions by trumpeter hornbills in fragmented landscapes. Proceedings of the Royal Society B: Biological Sciences 278, 2257-2264, doi:10.1098/rspb.2010.2383 (2011).

32 Galetti, M. et al. Functional extinction of birds drives rapid evolutionary changes in seed size. Science 340, 1086-1090, doi:10.1126/science.1233774 (2013).

33 Baker, W. J. \& Couvreur, T. L. P. Global biogeography and diversification of palms sheds light on the evolution of tropical lineages. II. Diversification history and origin of regional assemblages. Journal of Biogeography 40, 286-298, doi:10.1111/j.1365-2699.2012.02794.x (2013).

34 Moore, R. P., Robinson, W. D., Lovette, I. J. \& Robinson, T. R. Experimental evidence for extreme dispersal limitation in tropical forest birds. Ecology Letters 11, 960-968, doi:10.1111/j.1461-0248.2008.01196.x (2008).

35 Corlett, R. T. Frugivory and seed dispersal by vertebrates in tropical and subtropical Asia: An update. Global Ecology and Conservation 11, 1-22, doi:https://doi.org/10.1016/j.gecco.2017.04.007 (2017).

36 Fleming, T. H., Breitwisch, R. \& Whitesides, G. H. Patterns of tropical vertebrate frugivore diversity. Annual Review of Ecology and Systematics 18, 91-109, doi:10.1146/annurev.es.18.110187.000515 (1987).

37 Banin, L. et al. What controls tropical forest architecture? Testing environmental, structural and floristic drivers. Global Ecology and Biogeography 21, 1179-1190, doi:10.1111/j.14668238.2012.00778.x (2012).

38 Kissling, W. D. et al. Cenozoic imprints on the phylogenetic structure of palm species assemblages worldwide. Proceedings of the National Academy of Sciences of the United States of America 109, 7379-7384, doi:10.1073/pnas.1120467109 (2012).

39 Baker, W. J. \& Couvreur, T. L. P. in Biotic evolution and environmental change in Southeast Asia (eds D. Gower et al.) 164-190 (Cambridge University Press, 2012).

40 Bacon, C. D., Baker, W. J. \& Simmons, M. P. Miocene dispersal drives island radiations in the palm tribe Trachycarpeae (Arecaceae). Systematic Biology 61, 426-442, doi:10.1093/sysbio/syr123 (2012).

41 Dransfield, J. \& Beentje, H. The palms of Madagascar. (Royal Botanic Gardens Kew and The International Palm Society, 1995).

42 Diamond, J. M., Gilpin, M. E. \& Mayr, E. Species-distance relation for birds of the Solomon Archipelago, and the paradox of the great speciators. Proceedings of the National Academy of Sciences of the United States of America 73, 2160-2164 (1976).

43 Moyle, R. G., Filardi, C. E., Smith, C. E. \& Diamond, J. Explosive Pleistocene diversification and hemispheric expansion of a "great speciator". Proceedings of the National Academy of Sciences 106, 1863-1868, doi:10.1073/pnas.0809861105 (2009). 
54344 Baldwin, B. G. \& Sanderson, M. J. Age and rate of diversification of the Hawaiian

45 Hughes, C. \& Eastwood, R. Island radiation on a continental scale: Exceptional rates of plant diversification after uplift of the Andes. Proceedings of the National Academy of Sciences 103, 10334-10339, doi:10.1073/pnas.0601928103 (2006).

46 Kissling, W. D. et al. Quaternary and pre-Quaternary historical legacies in the global distribution of a major tropical plant lineage. Global Ecology and Biogeography 21, 909-921, doi:10.1111/j.1466-8238.2011.00728.x (2012).

47 Kitamura, S. Frugivory and seed dispersal by hornbills (Bucerotidae) in tropical forests. Acta Oecologica 37, 531-541 (2011).

48 Morici, C. in Ecologia Insular (eds JM Fernandez-Palacios \& C Morici) 81-122 (Asociacion Española de Ecología Terrestre, 2004).

49 Pintaud, J.-C. \& Jaffre, T. Patterns of diversity and endemism in palms on ultramafic rocks in New Caledonia. South African Journal of Science 97, 548-550 (2001).

50 Sanín, M. J. et al. The Neogene rise of the tropical Andes facilitated diversification of wax palms (Ceroxylon: Arecaceae) through geographical colonization and climatic niche separation. Botanical Journal of the Linnean Society 182, 303-317, doi:10.1111/boj.12419 (2016).

51 Svenning, J.-C. On the role of microenvironmental heterogeneity in the ecology and diversification of neotropical rain-forest palms (Arecaceae). The Botanical Review 67, 1-53, doi:10.1007/BF02857848 (2001).

52 Eiserhardt, W. L., Svenning, J.-C., Kissling, W. D. \& Balslev, H. Geographical ecology of the palms (Arecaceae): determinants of diversity and distributions across spatial scales. Annals of Botany 108, 1391-1416, doi:10.1093/aob/mcr146 (2011).

53 Herrera, C. M. Interspecific Variation in Fruit Shape: Allometry, Phylogeny, and Adaptation to Dispersal Agents. Ecology 73, 1832-1841, doi:10.2307/1940034 (1992).

54 Lomáscolo, S. B., Levey, D. J., Kimball, R. T., Bolker, B. M. \& Alborn, H. T. Dispersers shape fruit diversity in Ficus (Moraceae). Proceedings of the National Academy of Sciences 107, 14668-14672, doi:10.1073/pnas.1008773107 (2010).

55 Voigt, F. A. et al. A comparison of morphological and chemical fruit traits between two sites with different frugivore assemblages. Oecologia 141, 94-104, doi:10.1007/s00442-004-1654-8 (2004).

56 Dominy, N. J., Svenning, J. C. \& Li, W. H. Historical contingency in the evolution of primate color vision. Journal of Human Evolution 44, 25-45, doi:10.1016/s0047-2484(02)00167-7 (2003).

57 Ricklefs, R. E. \& Renner, S. S. Species richness within families of flowering plants. Evolution 48, 1619-1636, doi:10.2307/2410252 (1994).

58 Bouchenak-Khelladi, Y., Onstein, R. E., Xing, Y., Schwery, O. \& Linder, H. P. On the complexity of triggering evolutionary radiations. New Phytologist 207, 313-326, doi:10.1111/nph.13331 (2015).

59 Onstein, R. E. \& Linder, H. P. Beyond climate: convergence in fast evolving sclerophylls in Cape and Australian Rhamnaceae predates the mediterranean climate. Journal of Ecology 104, 665-677, doi:10.1111/1365-2745.12538 (2016).

60 Baker, W. J. et al. Complete generic-level phylogenetic analyses of palms (Arecaceae) with comparisons of supertree and supermatrix approaches. Syst Biol 58, 240-256 (2009).

61 Govaerts, R. \& Dransfield, J. World checklist of palms., (Royal Botanic Gardens Kew, 2005). 62 Kreft, H., Jetz, W., Mutke, J., Kier, G. \& Barthlott, W. Global diversity of island floras from a macroecological perspective. Ecology Letters 11, 116-127, doi:10.1111/j.14610248.2007.01129.x (2008).

63 Weigelt, P., Jetz, W. \& Kreft, H. Bioclimatic and physical characterization of the world's islands. Proceedings of the National Academy of Sciences 110, 15307-15312, doi:10.1073/pnas.1306309110 (2013).

64 Rabosky, D. L. \& Goldberg, E. E. Model inadequacy and mistaken inferences of traitdependent speciation. Systematic Biology 64, 340-355, doi:10.1093/sysbio/syu131 (2015). 


\section{Additional information}

633

634

635 (2009). (2014).

\section{Acknowledgements}

\section{Author contributions}

65 Maddison, W. P. \& FitzJohn, R. G. The unsolved challenge to phylogenetic correlation tests for categorical characters. Systematic Biology 64, 127-136, doi:10.1093/sysbio/syu070 (2015).

66 Davis, M. P., Midford, P. E. \& Maddison, W. Exploring power and parameter estimation of the BiSSE method for analyzing species diversification. BMC Evolutionary Biology 13, 1-11, doi:10.1186/1471-2148-13-38 (2013).

$67 \mathrm{R}$ Development Core Team. $R$ : a language and environment for statistical computing, version 3.1.0 (2014-04-10), <http://www.R-project.org> (2014).

68 Bruggeman, J., Heringa, J. \& Brandt, B. W. PhyloPars: estimation of missing parameter values using phylogeny. Nucleic Acids Research 37, W179-W184, doi:10.1093/nar/gkp370

69 Baker, W. J. \& Couvreur, T. L. P. Global biogeography and diversification of palms sheds light on the evolution of tropical lineages. I. Historical biogeography. Journal of Biogeography 40, 274-285, doi:10.1111/j.1365-2699.2012.02795.x (2013).

70 FitzJohn, R. G. Quantitative Traits and Diversification. Systematic Biology 59, 619-633, doi:10.1093/sysbio/syq053 (2010).

71 Rabosky, D. L. Automatic Detection of Key Innovations, Rate Shifts, and DiversityDependence on Phylogenetic Trees. PLOS ONE 9, e89543, doi:10.1371/journal.pone.0089543

We thank Henrik Balslev, Anders Barfod, Anne Blach-Overgaard, Finn Borchsenius, John Dransfield, Wolf Eiserhardt and María José Sanín for discussions about palm biology, John Dransfield and Andrew J. Henderson for the use of pictures for figure 1. W.D.K. was supported by the University of Amsterdam (starting grant), the Danish Council for Independent Research-Natural Sciences (grant 11106163), and the Netherlands Organisation for Scientific Research (grant 824.15.007). W.J.B. was supported by a grant from the Garfield Weston Foundation to the Global Tree Seed Bank Project at the Royal Botanic Gardens, Kew. J.C.S. was supported by the European Research Council (ERC-2012StG-310886-HISTFUNC), and also considers this work a contribution to his VILLUM Investigator project "Biodiversity Dynamics in a Changing World" funded by VILLUM FONDEN.

W.D.K. conceived the idea, W.D.K. and R.E.O. designed the study; W.D.K. and R.E.O. collected data; R.E.O. analysed the data; R.E.O. and W.D.K. wrote the manuscript; all authors discussed the results and commented on the manuscript.

Supplementary information is available for this paper.

Reprints and permissions information is available at www.nature.com/reprints.

Correspondence and requests for materials should be addressed to R.E.O and W.D.K.

$$
\text { How to cite this article: TO BE ADDED. }
$$


Page 18

\section{Competing interests}

638 The authors declare no competing financial interests. 

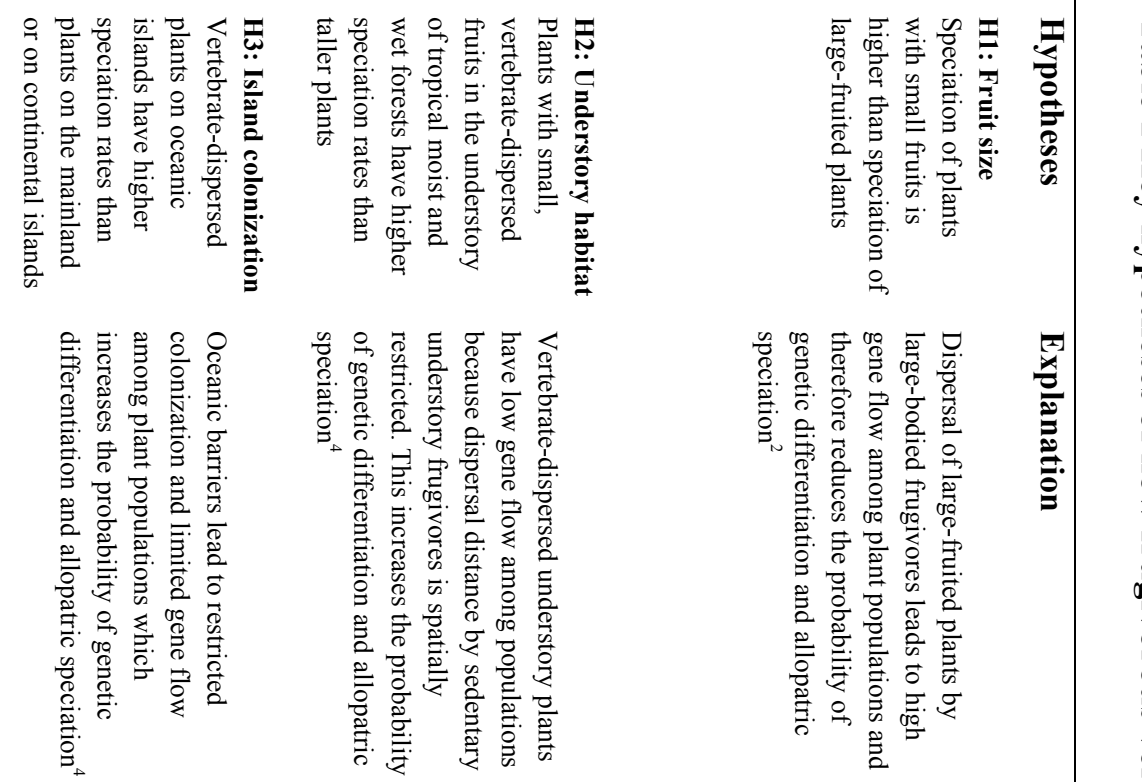

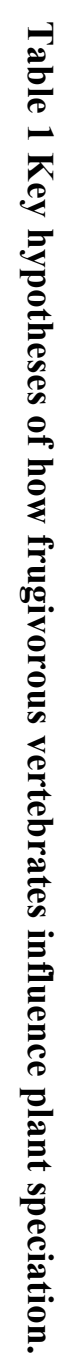

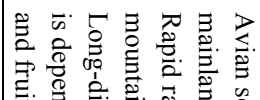

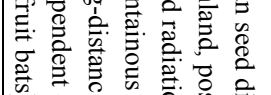

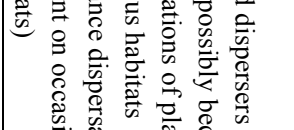

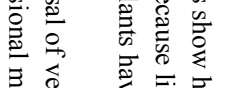

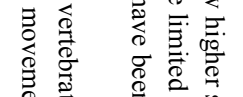

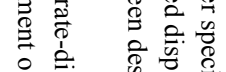

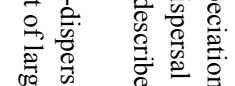

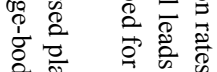

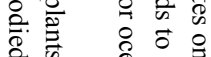

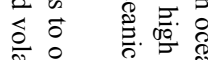

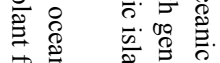

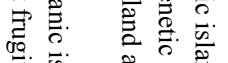

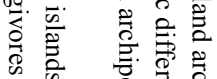

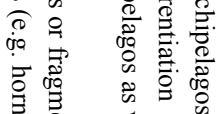

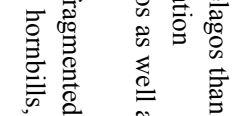

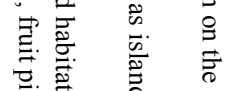

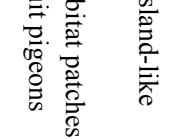

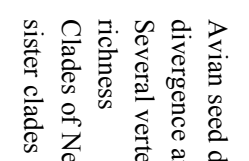

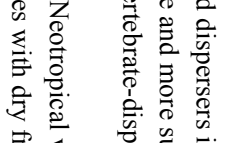

产.

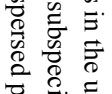

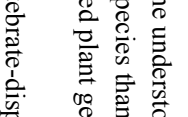

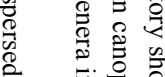

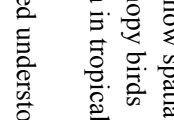

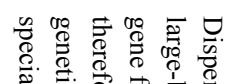

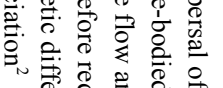

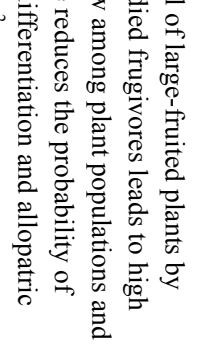

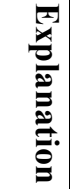

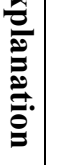

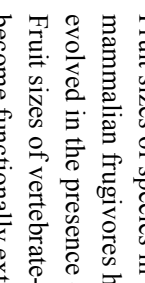

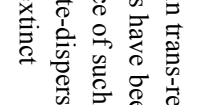

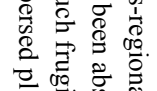

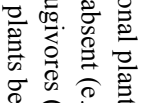

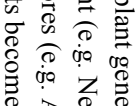

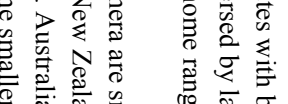

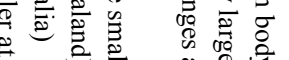

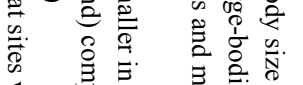

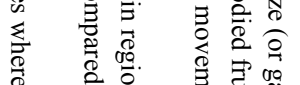

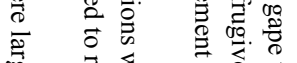

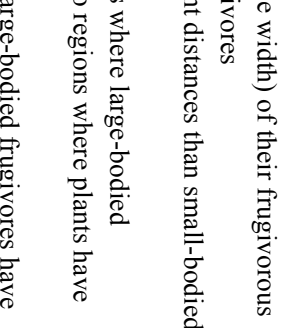




\section{Figures}

644 Figure 1 | Global variation in palm fruit size. (a) Fruit sizes of all species in the analysis $(n=1836$

645 extant palm species). The classification of small $(<4 \mathrm{~cm})$ and large $(\geq 4 \mathrm{~cm})$ fruits as used in the 646 models in this study is indicated, as well as the median $(m)$ and sample size $(n)$ for each of these

647 groups. (b-i) Pictures illustrating the diversity of vertebrate-dispersed fruits in palms, representing (b-

648 e) small-fruited and (f-i) large-fruited palms. (b) Iguanura elegans (John Dransfield); (c) Pinanga

649 disticha (John Dransfield); (d) Calamus erioacanthus (John Dransfield); (e) Ravenea dransfieldii

650 (John Dransfield); (f) Manicaria saccifera (John Dransfield); (g) Mauritia flexuosa (Andrew J.

651 Henderson); (h) Pholidocarpus sumatranus (John Dransfield); (i) Metroxylon sagu (William J. Baker).

652
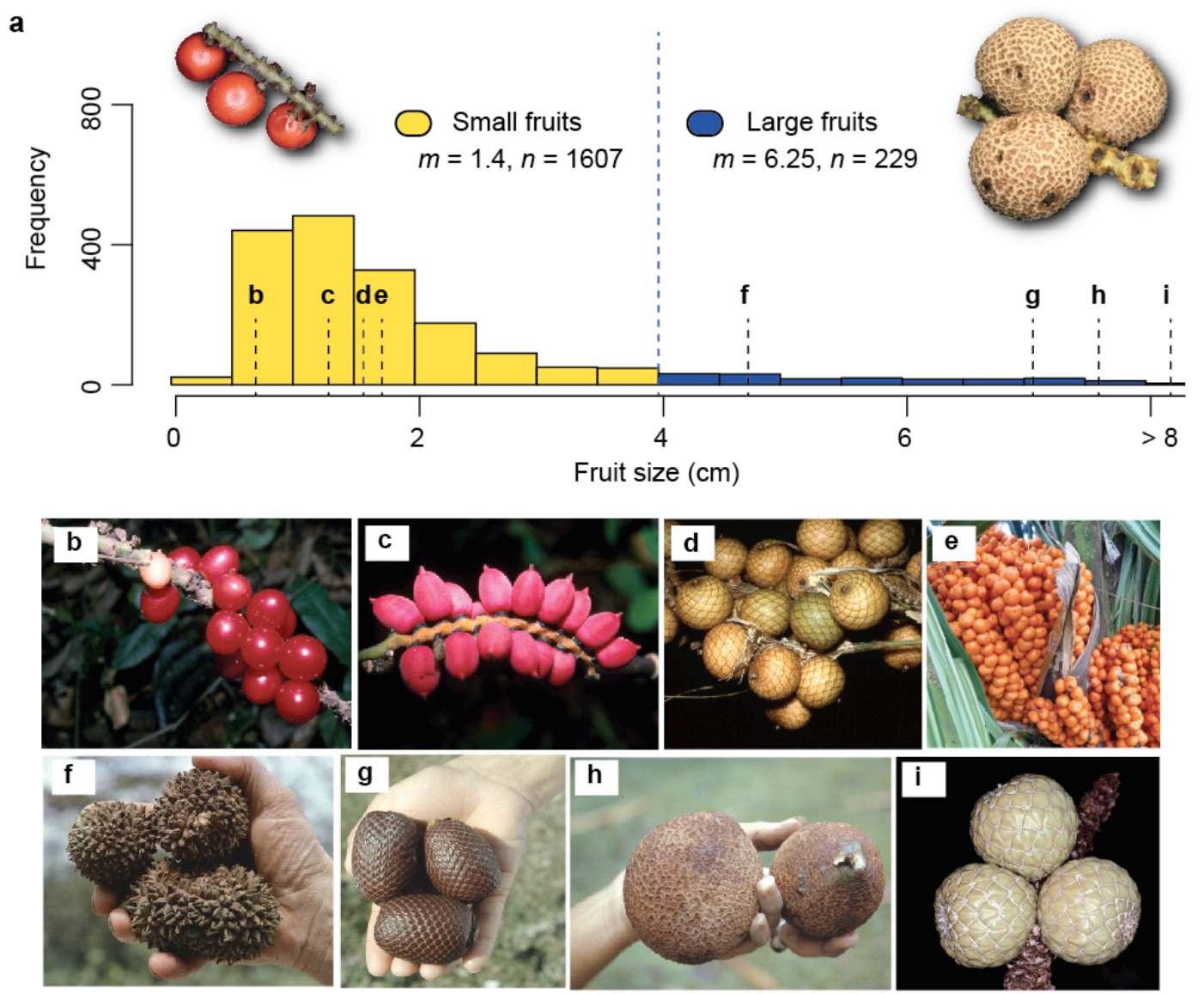
657 Figure 2 | Speciation rate estimates for palm lineages with small $(<4 \mathrm{~cm})$ and large $(\geq 4 \mathrm{~cm})$

658 fruits. Rates are inferred (a) globally as well as separately for (b) the New World (the Americas) and

659 (c) the Old World (Africa, Asia and Australia) using Binary State Speciation and Extinction (BiSSE)

660 models with 100 palm phylogenies. Box-and-whiskers indicate the $95 \%$ Bayesian credibility intervals

661 of the speciation rates as estimated through Bayesian Markov Chain Monte Carlo methods. Small-

662 fruited palm lineages show higher speciation rates than large-fruited palms globally and in the Old

663 World, but not in the New World (where the best model suggested an equal rate of both large and 664 small-fruited palms, see Supplementary Table 3).

665

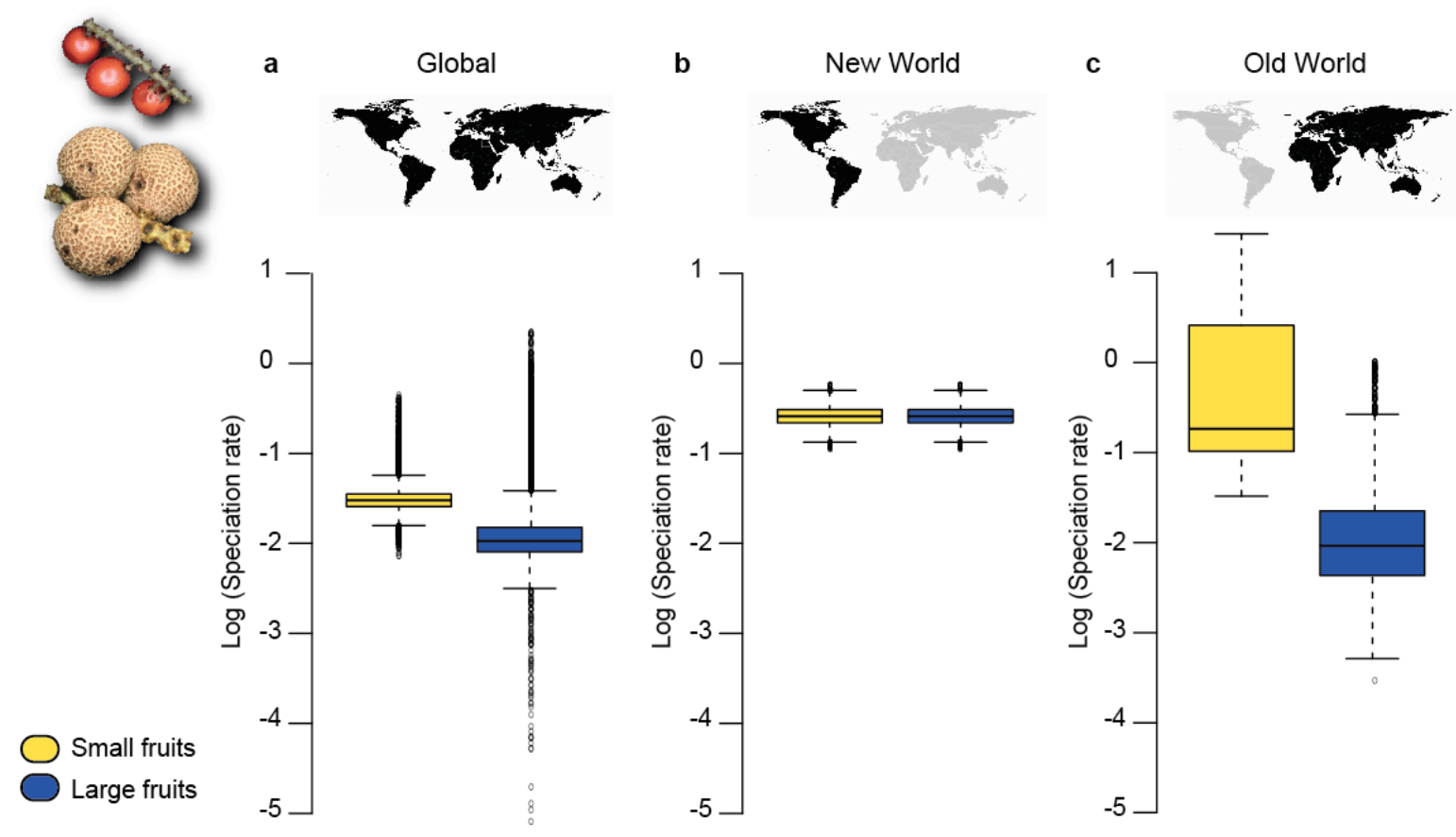


Figure 3 | Understory habitat and its effect on speciation rates for palm lineages with small $(<4$ cm) fruits. Rates are inferred (a) globally as well as separately for (b) the New World (the Americas) and (c) the Old World (Africa, Asia and Australia) using Multiple State Speciation and Extinction

672 (MuSSE) models with 100 palm phylogenies. Box-and-whiskers indicate the 95\% Bayesian credibility 673 intervals of the speciation rates as estimated through Bayesian Markov Chain Monte Carlo methods.

674 The base model indicates rates of large-fruited $(\geq 4 \mathrm{~cm})$ canopy palms. Small fruits and understory 675 habitat both add positively to the speciation rate as compared to the base model. In the global and New

676 World analyses an interaction term was supported, suggesting the highest rates for small-fruited 677 understory palms. No value is given for the interaction for the Old World since a model without it was 678 preferred by AIC (indicated by n.a. [not applicable]).

679

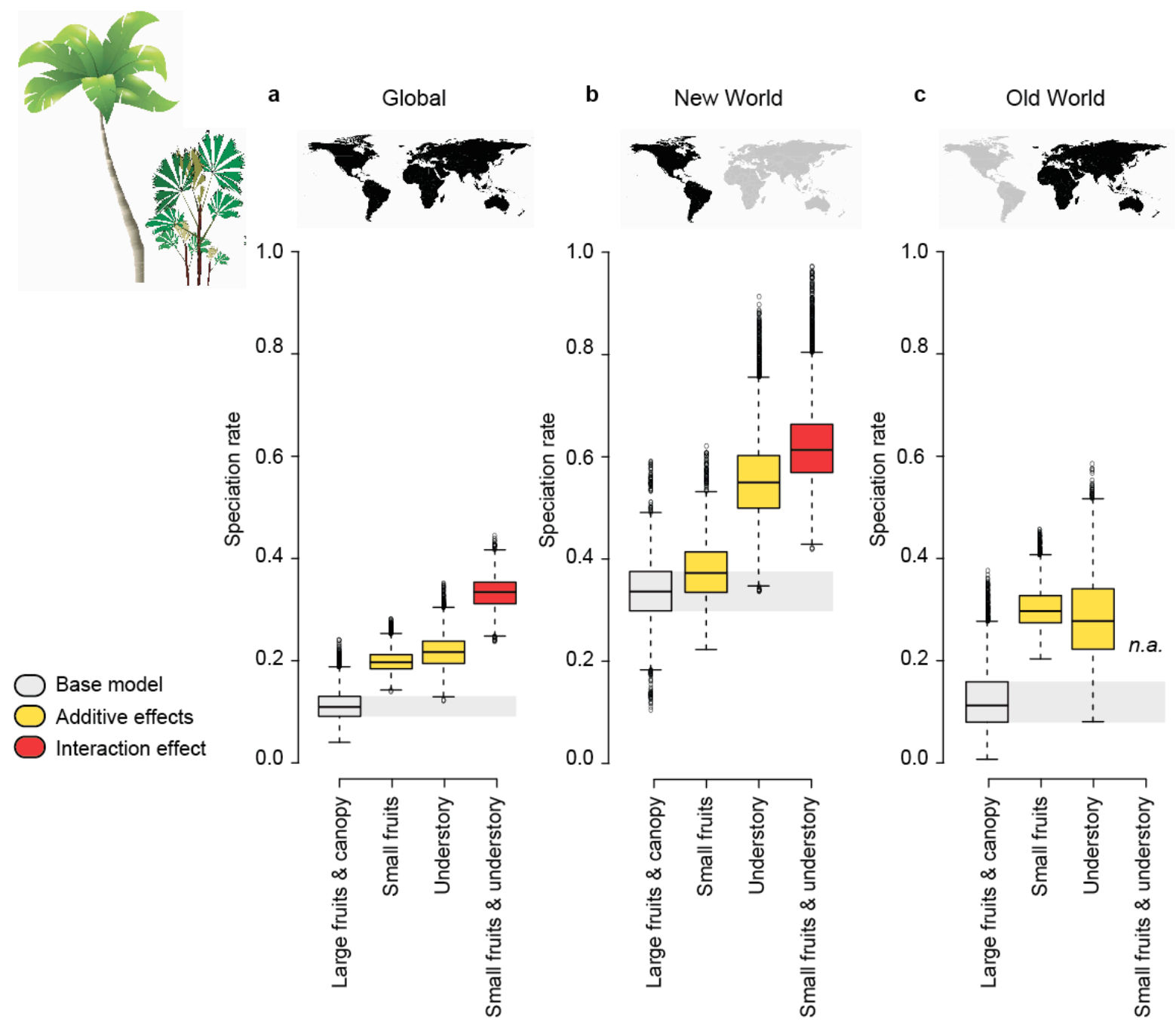


682 Figure 4 | Island colonization and its effect on speciation rates for palm lineages with small $(<4$

$683 \mathrm{~cm}$ ) fruits. Rates are inferred (a) globally as well as separately for (b) the New World (the Americas)

684 and (c) the Old World (Africa, Asia and Australia) using Multiple State Speciation and Extinction

685 (MuSSE) models with 100 palm phylogenies. Box-and-whiskers indicate the 95\% Bayesian credibility

686 intervals of the speciation rates as estimated through Bayesian Markov Chain Monte Carlo methods.

687 The base model indicates rates of large-fruited $(\geq 4 \mathrm{~cm})$ mainland or continental island-distributed

688 palms. Small fruits and island distribution both add positively to the speciation rate as compared to the

689 base model. In the global and Old World analyses an interaction term was supported, suggesting the

690 highest rates for small-fruited island-distributed palms. No value is given for the interaction for the

691 New World since a model without it was preferred by AIC (indicated by n.a. [not applicable]).

692

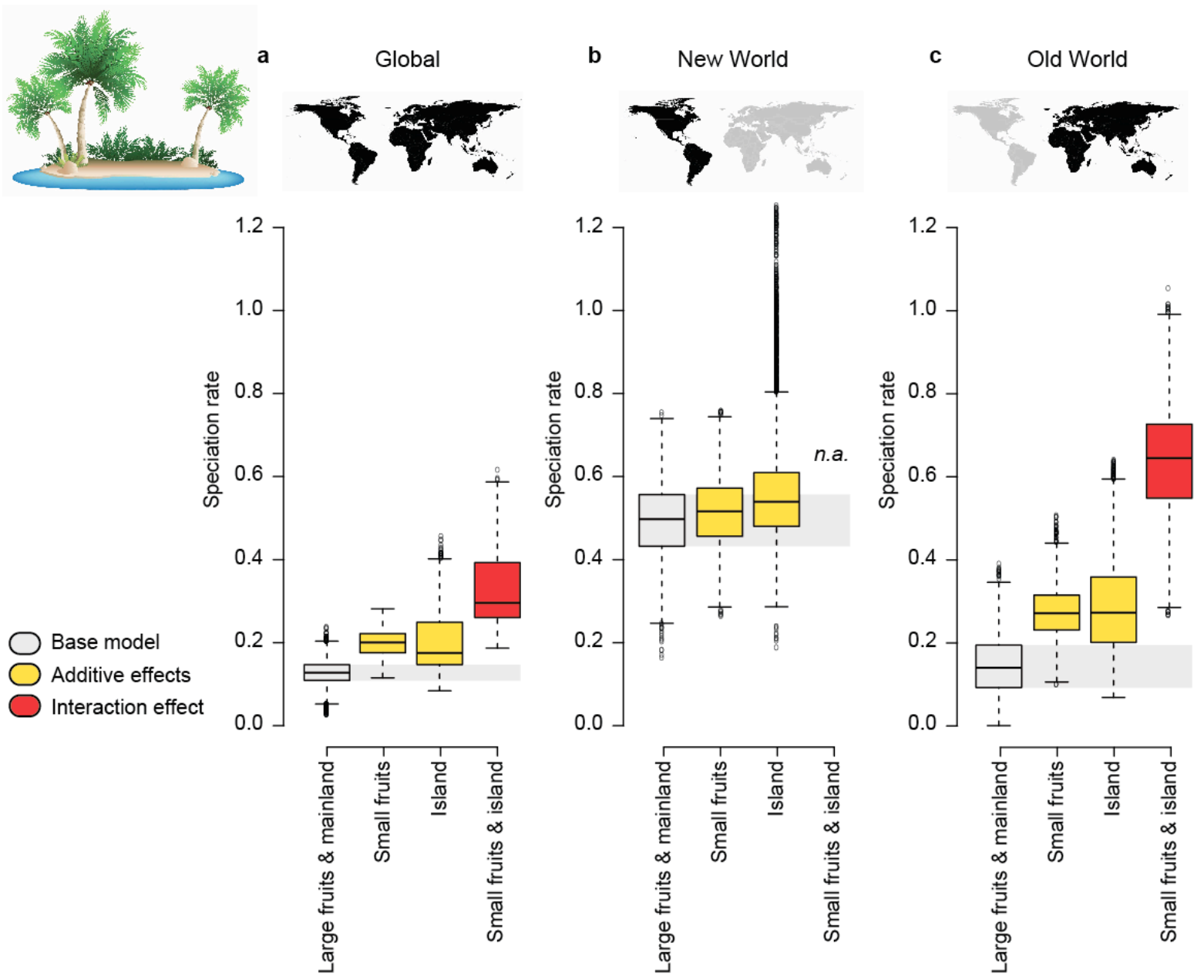




\section{SUPPLEMENTARY INFORMATION}

\section{Frugivory-related traits promote speciation of tropical palms}

Renske E. Onstein ${ }^{1, *}$, William J. Baker ${ }^{2}$, Thomas L. P. Couvreur ${ }^{3}$, Søren Faurby ${ }^{4.5}$, JensChristian Svenning ${ }^{6} \&$ W. Daniel Kissling ${ }^{1, *}$

${ }^{1}$ Institute for Biodiversity and Ecosystem Dynamics (IBED), University of Amsterdam, Amsterdam, The Netherlands

${ }^{2}$ Royal Botanic Gardens, Kew, Richmond, Surrey, UK

${ }^{3}$ Institut de Recherche pour le Développement, UMR-DIADE, Montpellier, France

${ }^{4}$ Department of Biological and Environmental Sciences, University of Gothenburg,Box 461, SE 405 30, Göteborg, Sweden

${ }^{5}$ Gothenburg Global Biodiversity Centre, Box 461, SE-405 30 Göteborg, Sweden

${ }^{6}$ Section for Ecoinformatics and Biodiversity, Department of Bioscience, Aarhus University, Aarhus, Denmark

*corresponding authors e-mails: onsteinre@gmail.com; wdkissling@gmail.com 


\section{CONTENT}

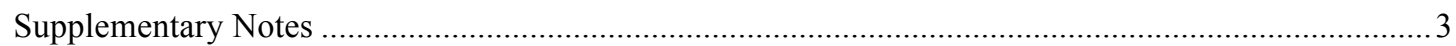

Supplementary Note 1. Fruit size-dependent diversification rates corrected for plant size................. 3

Supplementary Note 2. Performance of trait-based models. .................................................... 4

Supplementary Note 3 . Fruit size-dependent diversification rates............................................. 5

Supplementary Note 4. Fruit size as a continuous trait, and its effect on speciation rates.................. 6

Supplementary Note 5. Understory and island-dependent diversification rates. ............................. 7

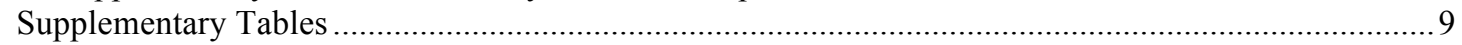

Supplementary Table 1 Summary statistics of fruit sizes for each palm genus. .............................9

Supplementary Table 2 Model selection for large/small fruits globally (BiSSE).......................... 14

Supplementary Table 3 Model selection for large/small fruits in the New World (BiSSE) .............. 15

Supplementary Table 4 Model selection for large/small fruits in the Old World (BiSSE)............... 16

Supplementary Table 5 Model selection after correcting for plant size (BiSSE). .......................... 17

Supplementary Table 6 Model selection after correcting for plant size (QuaSSE). ......................... 18

Supplementary Table 7 Models tested in the Multiple State Speciation and Extinction (MuSSE)

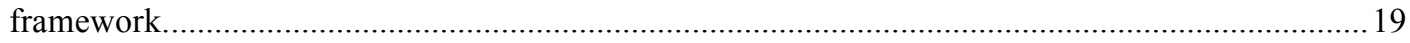

Supplementary Table 8 Model selection for fruit size and understory habitat (MuSSE). ...............20

Supplementary Table 9 Model selection for fruit size and island colonization (MuSSE)................21

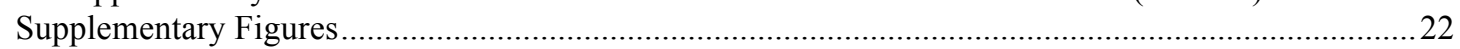

Supplementary Figure 1 | Correlation between fruit size and plant size in palms. ..........................22

Supplementary Figure 2 | Fruit size frequency distributions of palms..........................................23

Supplementary Figure 3 | Diversification rates under simulated binary traits (BiSSE)...................24

Supplementary Figure $4 \mid$ Diversification rates of small- and large-fruited palms (BiSSE).............25

Supplementary Figure 5 | Speciation rate in response to fruit size (QuaSSE). .............................26

Supplementary Figure 6 | Phylorate plot of speciation rates in palms (BAMM)..........................27

Supplementary Figure 7 | Trait interaction effects on diversification rates (MuSSE). .....................28

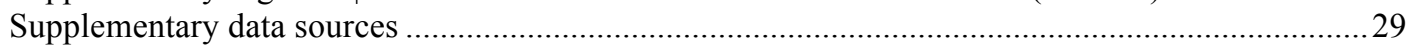

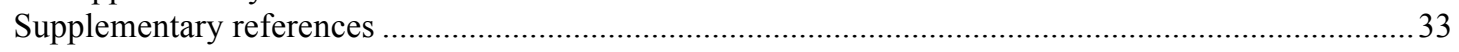




\section{Supplementary Notes}

\section{Supplementary Note 1. Fruit size-dependent diversification rates corrected for plant size.}

Methods. As a positive effect of small fruit size on speciation rates could be driven by a confounding effect of plant size on fruit size (i.e. smaller plants generally have smaller fruits and may have shorter generation times), we corrected for this by performing trait-dependent diversification analyses on the residuals of a linear regression model with log (fruit size) as the response variable and log (maximum stem height) as the explanatory variable (see Supplementary Fig. 1). The traits were log-transformed to approximate normality and to accommodate linear model assumptions such as normality in the residuals.

The linear regression model indicated a significant positive effect of $\log$ (maximum stem height $)$ on $\log$ (fruit size $)(\mathrm{df}=1683, \mathrm{~F}=115.98, \mathrm{p}<0.001$, model estimate $=0.142$, standard error $=0.232$ ), although the adjusted $\mathrm{R}^{2}$ was only 0.06 , indicating that ca. $6 \%$ of the variation in fruit size can be explained by palm maximum stem height. Model residuals (i.e. the non-explained variation in fruit size) were reassessed for their effect on speciation, extinction and transition rates with the BiSSE model (large fruit residuals $\geq 4 \mathrm{~cm}$ ), repeating the analyses as descibed in the main text (related to H1) (see Supplementary Table 5 for model selection). However, as these residuals do not represent 'true' small and large fruits, we also investigated the effect of residual log-tranformed fruit size on speciation rates using the Quantatative Speciation and Extinction model (QuaSSE) ${ }^{1}$. QuaSSE can be used to test the effect of a continuous trait on speciation rates by testing the fit of models describing the distribution of the response (i.e. speciation rate) to the trait (e.g. constant, linear or sigmoidal) (see Supplementary Table 6 for model selection). The best model was selected using likelihood-ratio tests (nested models) and the Akaike Information Criterion (AIC) (non-nested models). The relationship between residual fruit size and speciation rate resulting from the best model can be plotted to visualize the results (Supplementary Fig. 5).

Results. Our results indicate that after correcting for a plant size effect, speciation rates between small and large fruited palm lineages remain significantly different. Specifically, small-fruited palms show higher speciation rates than large-fruited palms (see Supplementary Fig. 4: compare residuals to global, New World and Old World distributions of Bayesian posterior rates for small- and large-fruited palms). Furthermore, the effect of palm residual fruit size $(\mathrm{cm})$ on speciation rates under the best-fitting QuaSSE model indicates that larger fruit sizes have lower rates of speciation than smaller fruit sizes, following a sigmoidal relationship (Supplementary Fig. 5). 


\section{Supplementary Note 2. Performance of trait-based models.}

The class of 'SSE' models has recently been criticized for high type I error rates ${ }^{2}$, suggesting that a significant effect of a trait on speciation or extinction rates can be detected even if it is not truly present. This error may be driven by the phylogenetic tree shape (i.e. distribution of branch lengths in the tree) $)^{2}$. We evaluated this bias by performing simulations as recommended by ref. ${ }^{2}$. First, we randomly evolved a neutral binary trait on 100 empirical palm phylogenies under three transition rate scenarios $(q=0.01, q=0.1 \text { and } q=1)^{2}$, providing a gradient from rare to frequent character state changes. This simulated trait is expected to be neutral with respect to speciation and extinction rates, as it evolved under a simple 'Markov discrete' $(\mathrm{Mk})^{3}$ model of evolution. We then evaluated the Bayesian credible intervals in speciation and extinction rates between these simulated trait states after running the Bayesian Markov Chain Monte Carlo chain for 10,000 generations on 100 palm phylogenies (Supplementary Fig. 3). We repeated this procedure using our observed transition rates (i.e. $\mathrm{q}_{\text {large to small }}=0.017$; $\mathrm{q}_{\text {small to large }}=0.006$ ). Importantly, strongly overlapping Bayesian credible intervals of speciation and extinction rates of the simulated binary traits would suggest that our empirical palm tree shapes unlikely biased our results, and type I error rates should be neglectable. Our results show that this is the case for all transition rate scenarios (Supplementary Fig. 3), suggesting that we can rely on the empirical results obtained from the 'SSE' models.

A second criticism on the 'SSE' models is that datasets should consist of sufficient species at the tips of the tree ( $>300$ species), a balanced distribution of trait states at the tips of the tree so that at least $10 \%$ of the species has a certain trait state $e^{4,5}$, and the trait should evolve multiple times to have sufficient independent events to evaluate correlations between trait states and speciation rates ${ }^{6}$. These criteria should be met to have the statistical power to reliably estimate the parameters in the SSE models. Our dataset comprises 1774 species, large fruits are found in $12 \%$, understory habitats in $36 \%$, and island distributions in $20 \%$ of all sampled palm species. Large fruits are found within 63, understory habitats within 73, and island distributions within 83 (out of 183) palm genera. Although this does not directly proof the repeated independent evolution of these 'traits' (i.e. these genera may form a clade), it does strongly suggest that at least several independent events have occurred. We thus have the statistical power to detect correlates between speciation rates and traits without erroneously relying on unbalanced character state distributions across the tree ${ }^{5}$, or pseudoreplication ${ }^{6}$. 


\section{Supplementary Note 3. Fruit size-dependent diversification rates.}

Methods. The Binary State Speciation and Extinction (BiSSE) model used to test the effect of fruit size on speciation rates (H1, see main text), simultaneously estimates speciation, extinction and transition rates, as these rates do not evolve independently from each other. The net diversification rate can be calculated by subtracting the extinction from the speciation rate. Although not directly related to the hypotheses presented in the main text, we here report the extinction, transition and net diversification rate estimates based on the best-fitting models for global, New World and Old World palms (see Supplementary Tables 2-4 for model selections).

Results. The Bayesian rates indicate that large-fruited Old World palm lineages have lower extinction rates than small-fruited Old World palm lineages (Supplementary Table 4, Supplementary Fig. 4). For the global and New World datasets we did not detect support for a different extinction rate for small- and large-fruited palms (Supplementary Tables 2 and 3). Globally, this has resulted in a higher net diversification rate (speciation rate minus extinction rate) for small-fruited compared to large-fruited palm lineages, but this difference is not recovered in the New World or Old World (overlapping 95\% Bayesian posterior densities, see Supplementary Fig. 4). Last, transition rates from small to large fruits have been lower than from large to small fruits in all analyses (globally, New World and Old World). These results suggest that although small fruits positively affect speciation rates globally and in the Old World (Fig. 2), the net diversification of small-fruited palms is only evident in the global analysis, as Old World small-fruited palms show high speciation rates, but also high extinction rates (resulting in high turnover rates). The transition rate results suggest that the evolution of smaller fruits from larger fruits has been more frequently observed during the diversification of palms than vice versa. All results are visualized in Supplementary Fig. 4. 
Supplementary Note 4. Fruit size as a continuous trait, and its effect on speciation rates.

Methods. In this study we compared the effect of small and large (megafaunal) fruits on speciation rates (main text). To do so, we defined megafaunal fruits as those with length $\geq 4$ $\mathrm{cm}$. However, fruit size in palms is a continuous trait, and we therefore also tested the effect of fruit size as a continuous trait on speciation rates, using the Bayesian Analysis of Macroevolutionary Mixtures approach implemented in BAMM version 2.5.0 ${ }^{7}$. BAMM explicitly accounts for diversification rate variation through time and uses a reversible jump MCMC algorithm to explore numerous candidate models of lineage diversification. These models thereby identify probabilities of diversification rate shifts (i.e. increases or slowdowns in diversification) on phylogenetic trees.

We ran BAMM on the palm Maximum Clade Credibility (MCC) tree ${ }^{8}$. Priors were estimated with the BAMMTools R package using the function "setBAMMpriors". A compound Poisson process for the prior probability of a rate shift along any branch was implemented, and we ran a MCMC for 10 million generations sampling event data every 5000 steps. We checked for convergence by plotting the log-likelihood trace of the MCMC output file and checked that the effective sample sizes of the runs exceeded 200.

BAMMTools was used to generate the mean phylorate plot, which represents the mean speciation rate sampled from the posterior at any point in time along any branch of the phylogenetic tree 9 .

To evaluate whether speciation rates are correlated to fruit size, we ran STructured Rate Permutations on Phylogenies (STRAPP) ${ }^{10}$, implemented in BAMMTools. The traitDependentBAMM function was used to compare the observed difference in speciation rate between palms that exhibit different fruit sizes to a background speciation rate through randomizing the estimated tip speciation rates from the BAMM outputs ${ }^{10}$.

Results. Palms show substantial speciation rate heterogeneity, congruent with the BAMM analysis performed previously on the genus-level phylogeny ${ }^{11}$ (Supplementary Fig. 6). We found that the speciation rate in palms correlates negatively with fruit size (one-tailed Pearson correlation, $r=-0.3, p<0.05$ ) assessed by 1000 permutations. This indicates that the observed correlation from the posterior samples is more negative (i.e. negative correlation between fruit size and speciation rate) than the correlations calculated with permuted rates, in more than $95 \%$ of the simulations. These results indicate that fruit size in palms is generally associated with low speciation rates, congruent with results from the binary classification of fruit size we made in the main text (Fig. 2). 


\section{Supplementary Note 5. Understory and island-dependent diversification rates.}

Methods. To disentangle the effect of two binary traits on speciation, extinction and transition rates, we implemented the Multiple State Speciation and Extinction model (MuSSE multistate) ${ }^{12}$. The model intercept of the MuSSE model (the 'base model') estimates speciation, extinction and transition rates when both traits are absent (illustrated with code 000 , in which the numbers refer to speciation, extinction and transition respectively, see Supplementary Table 7). 0 refers to absence of the traits, 1 to an additive effect of the traits, and 2 to an interaction effect of the traits. 000 therefore refers to, for example, palm lineages with large fruits that do not grow in the understory (absence of small fruits and understory habitat). Significant support for the additive effects of the traits on for example speciation rates (illustrated with code 100) or extinction rates (illustrated with code 010 ) or both (illustrated with code 110) would indicate that the individual traits affect speciation or extinction rates or both (speciation and extinction rates), respectively. Support for an interaction term (when both traits are present) will indicate whether these traits may interact in either a positive way (i.e. both traits increase speciation rates) or a negative way (i.e. both traits decrease speciation rates). This would be illustrated with code 210 for a significant interaction effect on speciation rates, and 120 for a significant interaction effect on extinction rates. Similarly, when additive effects on transition rates are detected (but not on speciation or extinction rates), this would be illustrated with code 001 .

To quantify trait-dependent diversification for both binary trait combinations (H2: small/large fruit size and understory yes/no; $\mathrm{H} 3$ : small/large fruit size and island colonization yes/no), we compared the likelihood of a total of sixteen models with increasing complexity, using a stepwise approach. We started with the base model (code 000) and added parameters for additive effects on speciation (code 100), extinction (code 010) or transition rates (code 001), or combinations of these (codes 110, 011, 101). Then we evaluated the support for including an interaction term for speciation (code 211) and extinction (code 121) rates to the model. The support for more complex models was evaluated using a likelihood ratio test (nested models) and the Akaike Information Criterion (AIC) (non-nested models). In case a more complex model was rejected, we accepted the best-fitting model given the fewest number of parameters. All models are described in Supplementary Table 7. A Bayesian Markov Chain Monte Carlo for the best-fitting model was run for 10,000 generations on 100 palm phylogenies for the global, New World and Old World palms separately (Supplementary Fig. 7).

Results. Here, we report the extinction, transition and net diversification rates as estimated with the Multiple State Speciation and Extinction (MuSSE) model for H2: small/large fruit size and understory yes/no (Supplementary Fig. 7a); and H3: small/large fruit size and island colonization yes/no (Supplementary Fig. 7b), globally, in New World and in Old World palm lineages. For speciation rate results see the main text.

The Bayesian rates indicate that small fruit size and understory habitat do not have an interactive effect on extinction rates (Supplementary Table 8). However, small fruit sizes do have a positive effect on extinction rates compared to large-fruited canopy palms in the global, New World and Old World analyses, congruent with the results obtained from the global and Old World BiSSE analyses (see Supplementary Note 3 and Supplementary Fig. 4). Transition rates from understory habitat to canopy habitat were higher than vice versa in all analyses (global, New World and Old World), and transition rates from large to small fruits 
were higher than from small to large fruits, congruent with the results obtained from the BiSSE analyses (see Supplementary Note 3 and Supplementary Fig. 4). The highest diversification rates were detected for small-fruited understory palms in the global and New World analyses, but not in the Old World (Supplementary Fig. 7a). This suggests that fruit size and understory habit act in synergy to increase diversification rates in global and New World palms.

Furthermore, the Bayesian rates indicate that small fruit size and island colonization do not have an interactive effect on extinction rates (Supplementary Table 9). However, small fruit sizes do have a positive effect on extinction rates globally and in the Old World compared to large-fruited mainland-distributed palms, congruent with the results obtained from the global and Old World BiSSE analyses (see Supplementary Note 3 and Supplementary Fig. 4). Transition rates from island to mainland were not significantly different from mainland to island (overlapping posterior densities in Supplementary Fig. 7b). The highest diversification rates were detected for small-fruited island-distributed palms in the global and Old World analyses, but not in the New World (Supplementary Fig. 7b). This suggests that fruit size and island colonization act in synergy to increase diversification rates in global and Old World palms. 


\section{Supplementary Tables}

\section{Supplementary Table 1 Summary statistics of fruit sizes for each palm genus.}

Fruit size characteristics and species richness for each palm genus are summarized as follows: mean $=$ average fruit size based on all species within the genus, $\mathrm{sd}=$ standard deviation, $\mathrm{var}=$ variance, $\#$ obs = number of species observations used for fruit measures, $\mathrm{se}=$ standard error, $\min =$ minimum, $\max =$ maximum, range $=$ maximum minus minimum, rich $=$ species richness, NA = not applicable.

*these genera are not dispersed by animals.

\begin{tabular}{|c|c|c|c|c|c|c|c|c|c|}
\hline Genus & mean & sd & var & \#obs & se & $\min$ & $\max$ & range & rich \\
\hline Acanthophoenix & 1.22 & 0.70 & 0.49 & 3 & 0.40 & 0.65 & 2 & 1.35 & 3 \\
\hline Acoelorrhaphe & 0.70 & NA & NA & 1 & NA & 0.70 & 0.70 & 0 & 1 \\
\hline Acrocomia & 2.68 & 1.48 & 2.20 & 3 & 0.86 & 1.30 & 4.25 & 2.95 & 8 \\
\hline Actinokentia & 2.60 & NA & NA & 1 & NA & 2.60 & 2.60 & 0 & 2 \\
\hline Actinorhytis & 10 & NA & NA & 1 & NA & 10 & 10 & 0 & 1 \\
\hline Adonidia & 2.50 & NA & NA & 1 & NA & 2.50 & 2.50 & 0 & 2 \\
\hline Aiphanes & 1.50 & 1.09 & 1.19 & 23 & 0.23 & 0.50 & 4.70 & 4.20 & 29 \\
\hline Allagoptera & 2.32 & 1.19 & 1.40 & 5 & 0.53 & 1.35 & 4.25 & 2.90 & 5 \\
\hline Ammandra & 10 & NA & NA & 1 & NA & 10 & 10 & 0 & 1 \\
\hline Aphandra & 35 & NA & NA & 1 & NA & 35 & 35 & 0 & 1 \\
\hline Archontophoenix & 1.60 & 0.48 & 0.23 & 6 & 0.20 & 1.10 & 2.30 & 1.20 & 6 \\
\hline Areca & 3.21 & 1.66 & 2.76 & 32 & 0.29 & 0.50 & 7.50 & 7 & 45 \\
\hline Arenga & 2.71 & 2.19 & 4.78 & 16 & 0.55 & 0.70 & 7 & 6.30 & 24 \\
\hline Asterogyne & 1.75 & 1.06 & 1.13 & 2 & 0.75 & 1 & 2.50 & 1.50 & 5 \\
\hline Astrocaryum & 4.92 & 1.70 & 2.90 & 31 & 0.31 & 1.20 & 8 & 6.80 & 37 \\
\hline Attalea & 7.58 & 2.37 & 5.60 & 39 & 0.38 & 3.75 & 12.50 & 8.75 & 67 \\
\hline Bactris & 1.73 & 0.88 & 0.77 & 75 & 0.10 & 0.50 & 5 & 4.50 & 77 \\
\hline Balaka & 2.41 & 0.95 & 0.91 & 5 & 0.43 & 1.60 & 4 & 2.40 & 9 \\
\hline Barcella & 3.50 & NA & NA & 1 & NA & 3.50 & 3.50 & 0 & 1 \\
\hline Basselinia & 0.80 & 0.24 & 0.06 & 11 & 0.07 & 0.40 & 1.20 & 0.80 & 14 \\
\hline Beccariophoenix & 2.95 & 0.78 & 0.61 & 2 & 0.55 & 2.40 & 3.50 & 1.10 & 2 \\
\hline Bentinckia & 1.50 & 0 & 0 & 2 & 0 & 1.50 & 1.50 & 0 & 2 \\
\hline Bismarckia & 4.40 & NA & NA & 1 & NA & 4.40 & 4.40 & 0 & 1 \\
\hline Borassodendron & 10.50 & 2.12 & 4.50 & 2 & 1.50 & 9 & 12 & 3 & 2 \\
\hline Borassus & 18.10 & 7.30 & 53.30 & 5 & 3.26 & 12 & 30 & 18 & 5 \\
\hline Brahea & 1.68 & 0.65 & 0.43 & 11 & 0.20 & 0.65 & 3 & 2.35 & 11 \\
\hline Brassiophoenix & 3.25 & 0.07 & 0.01 & 2 & 0.05 & 3.20 & 3.30 & 0.10 & 2 \\
\hline Burretiokentia & 3.88 & 4.55 & 20.67 & 5 & 2.03 & 1.60 & 12 & 10.40 & 5 \\
\hline Butia & 2.23 & 0.72 & 0.51 & 12 & 0.21 & 1.20 & 3.60 & 2.40 & 20 \\
\hline Calamus & 1.48 & 0.71 & 0.50 & 193 & 0.05 & 0.50 & 5 & 4.50 & 379 \\
\hline Calyptrocalyx & 1.51 & 0.89 & 0.79 & 26 & 0.17 & 0.40 & 5 & 4.60 & 26 \\
\hline Calyptrogyne & 1.23 & 0.51 & 0.26 & 8 & 0.18 & 0.21 & 1.75 & 1.54 & 17 \\
\hline
\end{tabular}




\begin{tabular}{|c|c|c|c|c|c|c|c|c|c|}
\hline Calyptronoma & 1.45 & 0.97 & 0.94 & 3 & 0.56 & 0.58 & 2.50 & 1.92 & 3 \\
\hline Carpentaria & 2 & NA & NA & 1 & NA & 2 & 2 & 0 & 1 \\
\hline Carpoxylon & 6 & NA & NA & 1 & NA & 6 & 6 & 0 & 1 \\
\hline Caryota & 2.45 & 0.72 & 0.51 & 11 & 0.22 & 1.40 & 3.50 & 2.10 & 14 \\
\hline Ceratolobus & 1.59 & 0.42 & 0.18 & 6 & 0.17 & 1.10 & 2.10 & 1 & 6 \\
\hline Ceroxylon & 1.76 & 0.16 & 0.03 & 10 & 0.05 & 1.50 & 2 & 0.50 & 12 \\
\hline Chamaedorea & 1.02 & 0.32 & 0.10 & 97 & 0.03 & 0.40 & 2.15 & 1.75 & 106 \\
\hline Chamaerops & 1 & NA & NA & 1 & NA & 1 & 1 & 0 & 1 \\
\hline Chambeyronia & 3.75 & 1.06 & 1.13 & 2 & 0.75 & 3 & 4.50 & 1.50 & 2 \\
\hline Chelyocarpus & 1.99 & 0.34 & 0.12 & 4 & 0.17 & 1.75 & 2.50 & 0.75 & 4 \\
\hline Chuniophoenix & 2.05 & 0.64 & 0.41 & 2 & 0.45 & 1.60 & 2.50 & 0.90 & 3 \\
\hline Clinosperma & 2.15 & 1.18 & 1.40 & 4 & 0.59 & 1 & 3.75 & 2.75 & 4 \\
\hline Clinostigma & 1.23 & 0.54 & 0.29 & 8 & 0.19 & 0.50 & 2.20 & 1.70 & 11 \\
\hline Coccothrinax & 1.21 & 1.23 & 1.51 & 20 & 0.27 & 0.50 & 6.30 & 5.80 & 51 \\
\hline $\operatorname{Cocos}^{*}$ & 22.50 & NA & NA & 1 & NA & 22.50 & 22.50 & 0 & 1 \\
\hline Colpothrinax & 1.62 & 0.32 & 0.10 & 3 & 0.19 & 1.25 & 1.85 & 0.60 & 3 \\
\hline Copernicia & 1.94 & 0.42 & 0.17 & 13 & 0.12 & 1.35 & 2.75 & 1.40 & 22 \\
\hline Corypha & 4.50 & 2.12 & 4.50 & 4 & 1.06 & 2.50 & 7.50 & 5 & 5 \\
\hline Cryosophila & 1.87 & 0.63 & 0.40 & 9 & 0.21 & 1.25 & 3.35 & 2.10 & 10 \\
\hline Cyphokentia & 1.23 & 0.04 & 0 & 2 & 0.03 & 1.20 & 1.25 & 0.05 & 2 \\
\hline Cyphophoenix & 1.89 & 0.48 & 0.23 & 4 & 0.24 & 1.20 & 2.30 & 1.10 & 4 \\
\hline Cyphosperma & 1.33 & 0.48 & 0.23 & 3 & 0.28 & 0.90 & 1.85 & 0.95 & 5 \\
\hline Cyrtostachys & 1.16 & 0.21 & 0.05 & 4 & 0.11 & 1 & 1.45 & 0.45 & 7 \\
\hline Daemonorops & 1.78 & 0.67 & 0.45 & 72 & 0.08 & 0.65 & 4.50 & 3.85 & 107 \\
\hline Deckenia & 1.20 & NA & $\mathrm{NA}$ & 1 & NA & 1.20 & 1.20 & 0 & 1 \\
\hline Desmoncus & 1.54 & 0.57 & 0.33 & 23 & 0.12 & 1 & 3.62 & 2.62 & 24 \\
\hline Dictyocaryum & 3.05 & 0.35 & 0.12 & 3 & 0.20 & 2.65 & 3.25 & 0.60 & 3 \\
\hline Dictyosperma & 1.25 & $\mathrm{NA}$ & NA & 1 & NA & 1.25 & 1.25 & 0 & 1 \\
\hline Dransfieldia & 1.55 & $\mathrm{NA}$ & $\mathrm{NA}$ & 1 & $\mathrm{NA}$ & 1.55 & 1.55 & 0 & 1 \\
\hline Drymophloeus & 1.13 & 0.81 & 0.66 & 2 & 0.58 & 0.55 & 1.70 & 1.15 & 3 \\
\hline Dypsis & 1.36 & 0.51 & 0.27 & 99 & 0.05 & 0.50 & 2.75 & 2.25 & 162 \\
\hline Elaeis & 3.50 & 1.06 & 1.13 & 2 & 0.75 & 2.75 & 4.25 & 1.50 & 2 \\
\hline Eleiodoxa & 2.50 & NA & $\mathrm{NA}$ & 1 & NA & 2.50 & 2.50 & 0 & 1 \\
\hline Eremospatha & 2.51 & 0.44 & 0.20 & 8 & 0.16 & 1.75 & 3.25 & 1.50 & 11 \\
\hline Eugeissona & 6.90 & 1.67 & 2.80 & 5 & 0.75 & 5 & 9 & 4 & 6 \\
\hline Euterpe & 1.31 & 0.34 & 0.12 & 7 & 0.13 & 1.05 & 2 & 0.95 & 7 \\
\hline Gaussia & 1.26 & 0.26 & 0.07 & 5 & 0.12 & 1 & 1.55 & 0.55 & 5 \\
\hline Geonoma & 0.85 & 0.27 & 0.07 & 63 & 0.03 & 0.53 & 1.89 & 1.36 & 68 \\
\hline Guihaia & 0.80 & 0.28 & 0.08 & 2 & 0.20 & 0.60 & 1 & 0.40 & 2 \\
\hline Hedyscepe & 4 & NA & NA & 1 & NA & 4 & 4 & 0 & 1 \\
\hline Hemithrinax & 0.90 & NA & $\mathrm{NA}$ & 1 & $\mathrm{NA}$ & 0.90 & 0.90 & 0 & 3 \\
\hline Heterospathe & 1.22 & 0.58 & 0.33 & 27 & 0.11 & 0.50 & 3.25 & 2.75 & 41 \\
\hline Howea & 3.75 & 0.35 & 0.13 & 2 & 0.25 & 3.50 & 4 & 0.50 & 2 \\
\hline Hydriastele & 1.13 & 0.32 & 0.10 & 25 & 0.06 & 0.60 & 1.80 & 1.20 & 49 \\
\hline
\end{tabular}




\begin{tabular}{|c|c|c|c|c|c|c|c|c|c|}
\hline Hyophorbe & 2.53 & 0.90 & 0.81 & 4 & 0.45 & 1.80 & 3.80 & 2 & 5 \\
\hline Hyospathe & 1.08 & 0.16 & 0.03 & 3 & 0.09 & 0.90 & 1.20 & 0.30 & 4 \\
\hline Hyphaene & 6.29 & 1.32 & 1.74 & 7 & 0.50 & 4.50 & 8.50 & 4 & 8 \\
\hline Iguanura & 1.30 & 0.54 & 0.29 & 17 & 0.13 & 0.60 & 2.40 & 1.80 & 32 \\
\hline Iriartea & 2.35 & NA & NA & 1 & NA & 2.35 & 2.35 & 0 & 1 \\
\hline Iriartella & 1.38 & 0.25 & 0.06 & 2 & 0.18 & 1.20 & 1.55 & 0.35 & 2 \\
\hline Itaya & 2.25 & NA & NA & 1 & NA & 2.25 & 2.25 & 0 & 1 \\
\hline Johannesteijsmannia & 4.20 & 1.13 & 1.28 & 2 & 0.80 & 3.40 & 5 & 1.60 & 4 \\
\hline Juania & 1.65 & NA & NA & 1 & NA & 1.65 & 1.65 & 0 & 1 \\
\hline Jubaea & 3.75 & NA & NA & 1 & NA & 3.75 & 3.75 & 0 & 1 \\
\hline Jubaeopsis & 3 & NA & NA & 1 & NA & 3 & 3 & 0 & 1 \\
\hline Kentiopsis & 1.95 & 0.21 & 0.04 & 4 & 0.10 & 1.70 & 2.20 & 0.50 & 4 \\
\hline Kerriodoxa & 4 & NA & $\mathrm{NA}$ & 1 & NA & 4 & 4 & 0 & 1 \\
\hline Korthalsia & 1.64 & 0.68 & 0.47 & 23 & 0.14 & 0.80 & 3.50 & 2.70 & 27 \\
\hline Laccospadix & 1.35 & NA & NA & 1 & NA & 1.35 & 1.35 & 0 & 1 \\
\hline Laccosperma & 1.63 & 0.30 & 0.09 & 5 & 0.13 & 1.35 & 2 & 0.65 & 6 \\
\hline Lanonia & 0.79 & 0.11 & 0.01 & 7 & 0.04 & 0.65 & 1 & 0.35 & 8 \\
\hline Latania & 5 & 1.32 & 1.75 & 3 & 0.76 & 4 & 6.50 & 2.50 & 3 \\
\hline Lemurophoenix & 0.50 & NA & NA & 1 & NA & 0.50 & 0.50 & 0 & 1 \\
\hline Leopoldinia & 3.32 & 0.68 & 0.46 & 2 & 0.48 & 2.84 & 3.80 & 0.96 & 2 \\
\hline Lepidocaryum & 2.25 & NA & NA & 1 & NA & 2.25 & 2.25 & 0 & 1 \\
\hline Lepidorrhachis & 1.20 & NA & NA & 1 & NA & 1.20 & 1.20 & 0 & 1 \\
\hline Leucothrinax & 0.70 & NA & NA & 1 & NA & 0.70 & 0.70 & 0 & 1 \\
\hline Licuala & 1.19 & 0.56 & 0.31 & 99 & 0.06 & 0.45 & 4 & 3.55 & 162 \\
\hline Linospadix & 1.31 & 0.47 & 0.22 & 6 & 0.19 & 0.70 & 2.15 & 1.45 & 7 \\
\hline Livistona & 1.61 & 0.67 & 0.45 & 26 & 0.13 & 0.80 & 3.25 & 2.45 & 28 \\
\hline Lodoicea* & 45 & NA & NA & 1 & NA & 45 & 45 & 0 & 1 \\
\hline Loxococcus & 2.50 & NA & NA & 1 & NA & 2.50 & 2.50 & 0 & 1 \\
\hline Lytocaryum & 2.58 & 0.81 & 0.66 & 2 & 0.58 & 2 & 3.15 & 1.15 & 4 \\
\hline Manicaria & 35 & NA & NA & 1 & NA & 35 & 35 & 0 & 2 \\
\hline Marojejya & 2.10 & 0.21 & 0.05 & 2 & 0.15 & 1.95 & 2.25 & 0.30 & 2 \\
\hline Masoala & 2.85 & 0.57 & 0.32 & 2 & 0.40 & 2.45 & 3.25 & 0.80 & 2 \\
\hline Mauritia & 6.38 & 0.88 & 0.78 & 2 & 0.63 & 5.75 & 7 & 1.25 & 2 \\
\hline Mauritiella & 3.25 & 1.15 & 1.31 & 3 & 0.66 & 2.25 & 4.50 & 2.25 & 4 \\
\hline Maxburretia & 0.98 & 0.04 & 0 & 2 & 0.03 & 0.95 & 1 & 0.05 & 3 \\
\hline Medemia & 4.50 & NA & NA & 1 & NA & 4.50 & 4.50 & 0 & 1 \\
\hline Metroxylon & 10.10 & 2.25 & 5.05 & 5 & 1 & 7 & 12.50 & 5.50 & 7 \\
\hline Myrialepis & 2.50 & NA & NA & 1 & NA & 2.50 & 2.50 & 0 & 1 \\
\hline Nenga & 3.70 & 1.96 & 3.86 & 5 & 0.88 & 1.40 & 6.50 & 5.10 & 5 \\
\hline Neonicholsonia & 0.95 & NA & NA & 1 & NA & 0.95 & 0.95 & 0 & 1 \\
\hline Neoveitchia & 5.50 & 0.71 & 0.50 & 2 & 0.50 & 5 & 6 & 1 & 2 \\
\hline Nephrosperma & 1.20 & NA & NA & 1 & NA & 1.20 & 1.20 & 0 & 1 \\
\hline Normanbya & 4.25 & NA & NA & 1 & NA & 4.25 & 4.25 & 0 & 1 \\
\hline Nypa* & 11.50 & NA & NA & 1 & NA & 11.50 & 11.50 & 0 & 1 \\
\hline
\end{tabular}




\begin{tabular}{|c|c|c|c|c|c|c|c|c|c|}
\hline Oenocarpus & 2.14 & 0.65 & 0.42 & 9 & 0.22 & 1.40 & 3.50 & 2.10 & 9 \\
\hline Oncocalamus & 1.97 & 0.06 & 0 & 3 & 0.03 & 1.90 & 2 & 0.10 & 5 \\
\hline Oncosperma & 1.28 & 0.30 & 0.09 & 4 & 0.15 & 1 & 1.70 & 0.70 & 5 \\
\hline Orania & 3.76 & 1.77 & 3.13 & 16 & 0.44 & 0.60 & 6.50 & 5.90 & 28 \\
\hline Oraniopsis & 3.40 & NA & NA & 1 & NA & 3.40 & 3.40 & 0 & 1 \\
\hline Parajubaea & 4.50 & 0.90 & 0.81 & 3 & 0.52 & 3.50 & 5.25 & 1.75 & 3 \\
\hline Pelagodoxa & 12.50 & NA & NA & 1 & NA & 12.50 & 12.50 & 0 & 1 \\
\hline Phoenicophorium & 0.80 & NA & NA & 1 & NA & 0.80 & 0.80 & 0 & 1 \\
\hline Phoenix & 2.20 & 1.41 & 2 & 14 & 0.38 & 1.30 & 7 & 5.70 & 14 \\
\hline Pholidocarpus & 7.10 & 3.03 & 9.18 & 5 & 1.35 & 4 & 11.50 & 7.50 & 6 \\
\hline Pholidostachys & 1.95 & 0.55 & 0.31 & 7 & 0.21 & 1.22 & 2.86 & 1.64 & 8 \\
\hline Physokentia & 2.01 & 0.55 & 0.31 & 6 & 0.23 & 1.20 & 2.55 & 1.35 & 7 \\
\hline Phytelephas & 9 & 2.68 & 7.17 & 4 & 1.34 & 7.50 & 13 & 5.50 & 6 \\
\hline Pigafetta & 0.90 & 0 & 0 & 2 & 0 & 0.90 & 0.90 & 0 & 2 \\
\hline Pinanga & 1.59 & 0.57 & 0.33 & 101 & 0.06 & 0.40 & 4.50 & 4.10 & 138 \\
\hline Plectocomia & 2.28 & 0.46 & 0.21 & 10 & 0.15 & 1.50 & 3 & 1.50 & 15 \\
\hline Plectocomiopsis & 2.59 & 0.12 & 0.02 & 5 & 0.06 & 2.50 & 2.75 & 0.25 & 6 \\
\hline Podococcus & 2.50 & NA & NA & 1 & NA & 2.50 & 2.50 & 0 & 2 \\
\hline Pogonotium & 1.47 & 0.21 & 0.04 & 3 & 0.12 & 1.30 & 1.70 & 0.40 & 3 \\
\hline Ponapea & 3.08 & 0.88 & 0.77 & 3 & 0.51 & 2.25 & 4 & 1.75 & 4 \\
\hline Prestoea & 1 & 0.19 & 0.04 & 9 & 0.06 & 0.85 & 1.40 & 0.55 & 10 \\
\hline Pritchardia & 3.09 & 1.47 & 2.15 & 27 & 0.28 & 0.60 & 7 & 6.40 & 28 \\
\hline Pseudophoenix & 1.97 & 0.82 & 0.67 & 4 & 0.41 & 1.30 & 3.07 & 1.77 & 4 \\
\hline Ptychococcus & 3.10 & 2.69 & 7.22 & 2 & 1.90 & 1.20 & 5 & 3.80 & 2 \\
\hline Ptychosperma & 1.50 & 0.25 & 0.06 & 24 & 0.05 & 1 & 2 & 1 & 30 \\
\hline Raphia & 7.05 & 1.61 & 2.60 & 19 & 0.37 & 5 & 11.50 & 6.50 & 20 \\
\hline Ravenea & 1.57 & 0.60 & 0.35 & 16 & 0.15 & 0.75 & 2.85 & 2.10 & 20 \\
\hline Reinhardtia & 1.58 & 0.28 & 0.08 & 6 & 0.11 & 1.20 & 2 & 0.80 & 6 \\
\hline Retispatha & 2 & $\mathrm{NA}$ & $\mathrm{NA}$ & 1 & $\mathrm{NA}$ & 2 & 2 & 0 & 1 \\
\hline Rhapidophyllum & 2 & NA & NA & 1 & NA & 2 & 2 & 0 & 1 \\
\hline Rhapis & 1.17 & 0.78 & 0.60 & 9 & 0.26 & 0.70 & 2.95 & 2.25 & 11 \\
\hline Rhopaloblaste & 2.17 & 0.77 & 0.60 & 6 & 0.32 & 1.10 & 3.25 & 2.15 & 6 \\
\hline Rhopalostylis & 1.35 & 0.07 & 0.01 & 2 & 0.05 & 1.30 & 1.40 & 0.10 & 2 \\
\hline Roscheria & 1 & NA & $\mathrm{NA}$ & 1 & $\mathrm{NA}$ & 1 & 1 & 0 & 1 \\
\hline Roystonea & 1.29 & 0.15 & 0.02 & 10 & 0.05 & 1 & 1.50 & 0.50 & 10 \\
\hline Sabal & 1.34 & 0.37 & 0.14 & 14 & 0.10 & 0.80 & 1.85 & 1.05 & 14 \\
\hline Salacca & 5.24 & 2.15 & 4.63 & 12 & 0.62 & 1.80 & 8 & 6.20 & 22 \\
\hline Saribus & 1.72 & 1.11 & 1.23 & 9 & 0.37 & 0.39 & 4 & 3.61 & 9 \\
\hline Satakentia & 1.30 & NA & NA & 1 & NA & 1.30 & 1.30 & 0 & 1 \\
\hline Satranala & 5.60 & NA & NA & 1 & NA & 5.60 & 5.60 & 0 & 1 \\
\hline Schippia & 2.50 & NA & NA & 1 & $\mathrm{NA}$ & 2.50 & 2.50 & 0 & 1 \\
\hline Sclerosperma & 3.67 & 0.76 & 0.58 & 3 & 0.44 & 3 & 4.50 & 1.50 & 3 \\
\hline Serenoa & 2.05 & NA & $\mathrm{NA}$ & 1 & $\mathrm{NA}$ & 2.05 & 2.05 & 0 & 1 \\
\hline Socratea & 3.50 & 0.71 & 0.50 & 4 & 0.35 & 3 & 4.50 & 1.50 & 5 \\
\hline
\end{tabular}




\begin{tabular}{|c|c|c|c|c|c|c|c|c|c|}
\hline Sommieria & 1.20 & NA & NA & 1 & NA & 1.20 & 1.20 & 0 & 1 \\
\hline Syagrus & 3.39 & 1.24 & 1.53 & 49 & 0.18 & 2 & 7 & 5 & 53 \\
\hline Synechanthus & 2.05 & 0.42 & 0.18 & 2 & 0.30 & 1.75 & 2.35 & 0.60 & 2 \\
\hline Tahina & 3.20 & NA & NA & 1 & NA & 3.20 & 3.20 & 0 & 1 \\
\hline Tectiphiala & 1.10 & NA & NA & 1 & NA & 1.10 & 1.10 & 0 & 1 \\
\hline Thrinax & 0.80 & 0.13 & 0.02 & 3 & 0.08 & 0.70 & 0.95 & 0.25 & 3 \\
\hline Trachycarpus & 1.05 & 0.32 & 0.10 & 8 & 0.11 & 0.70 & 1.70 & 1 & 9 \\
\hline Trithrinax & 0.98 & 0.16 & 0.03 & 3 & 0.09 & 0.80 & 1.10 & 0.30 & 4 \\
\hline Veitchia & 2.71 & 1.32 & 1.74 & 7 & 0.50 & 1.50 & 5 & 3.50 & 11 \\
\hline Verschaffeltia & 2.50 & NA & NA & 1 & NA & 2.50 & 2.50 & 0 & 1 \\
\hline Voanioala & 7.50 & NA & NA & 1 & NA & 7.50 & 7.50 & 0 & 1 \\
\hline Wallichia & 1.56 & 0.42 & 0.18 & 5 & 0.19 & 1.10 & 2.20 & 1.10 & 8 \\
\hline Washingtonia & 0.80 & 0.28 & 0.08 & 2 & 0.20 & 0.60 & 1 & 0.40 & 2 \\
\hline Welfia & 3.21 & NA & NA & 1 & NA & 3.21 & 3.21 & 0 & 1 \\
\hline Wendlandiella & 0.90 & NA & NA & 1 & NA & 0.90 & 0.90 & 0 & 1 \\
\hline Wettinia & 2.79 & 0.80 & 0.64 & 20 & 0.18 & 1.70 & 4.50 & 2.80 & 21 \\
\hline Wodyetia & 5.75 & NA & NA & 1 & NA & 5.75 & 5.75 & 0 & 1 \\
\hline Zombia & 1.75 & NA & NA & 1 & NA & 1.75 & 1.75 & 0 & 1 \\
\hline
\end{tabular}




\section{Supplementary Table 2 Model selection for large/small fruits globally (BiSSE).}

Eight Binary State Speciation and Extinction (BiSSE) models were fitted to the palm Maximum Clade Credibility (MCC) phylogenetic tree to compare speciation, extinction and transition rates of small- vs. large-fruited palm lineages. The best-fitting model given the fewest number of parameters (i.e. 5 Df) is indicated in bold (*). This model indicates that, globally, small- and large-fruited palm lineages have different speciation rates, but similar extinction rates.

\begin{tabular}{|c|c|c|c|c|c|}
\hline Model constraints & Df & LnLik & AIC & ChiSq & P \\
\hline Full (no constrain) & 6 & -5978.8 & 11970 & & \\
\hline$\lambda_{\text {small }} \sim \lambda_{\text {large }}$ & 5 & -5990.1 & 11990 & 22.610 & $2 \mathrm{e}-06 * * *$ \\
\hline${ }^{*} \mu_{\text {small }} \sim \mu_{\text {large }}$ & $\mathbf{5}$ & $\mathbf{- 5 9 7 9 . 4}$ & $\mathbf{1 1 9 6 9}$ & $\mathbf{1 . 1 4 4}$ & $\mathbf{0 . 2 8 5}$ \\
\hline $\mathrm{q}_{\text {small } \rightarrow \text { large }} \sim \mathrm{q}_{\text {large }} \rightarrow$ small & 5 & -5986.1 & 11982 & 14.590 & $0.0001 * * *$ \\
\hline$\lambda_{\text {small }} \sim \lambda_{\text {large, }} \mu_{\text {small }} \sim \mu_{\text {large }}$ & 4 & -6026.9 & 12062 & 96.045 & $\begin{array}{c}<2.2 \mathrm{e}-16 \\
* * *\end{array}$ \\
\hline $\begin{array}{c}\lambda_{\text {small }} \sim \lambda_{\text {large, }} \mathrm{q}_{\text {small }} \rightarrow \text { large } \\
\mathrm{q}_{\text {large }} \rightarrow \text { small }\end{array}$ & 4 & -5990.7 & 11989 & 23.621 & $\begin{array}{c}7.4 \mathrm{e}-06 \\
* * *\end{array}$ \\
\hline $\begin{array}{c}\mu_{\text {small }} \sim \mu_{\text {large, }} \mathrm{q}_{\text {small }} \rightarrow \text { large } \\
\mathrm{q}_{\text {large }} \rightarrow \text { small }\end{array}$ & 4 & -5988.7 & 11985 & 19.732 & $\begin{array}{c}5.2 \mathrm{e}-05 \\
* * *\end{array}$ \\
\hline $\begin{array}{c}\lambda_{\text {small }} \sim \lambda_{\text {large, }}, \mu_{\text {small }} \sim \mu_{\text {large, }} \\
\mathrm{q}_{\text {small } \rightarrow \text { large }} \sim \mathrm{q}_{\text {large }} \rightarrow \text { small }\end{array}$ & 3 & -6033.1 & 12072 & 108.491 & $\begin{array}{c}<2.2 \mathrm{e}-16 \\
* * *\end{array}$ \\
\hline
\end{tabular}

$\mathrm{Df}=$ degrees of freedom, $\mathrm{LnLik}=\log$ likelihood, $\mathrm{AIC}=$ Akaike Information Criterion, $\mathrm{ChiSq}$

$=$ Chi-square, $\mathrm{P}=$ significance of the model compared to the full model, $\lambda=$ speciation rate, $\mu$ $=$ extinction rate, $\mathrm{q}=$ transition rate, $\sim=$ equal to (constrain). Signif. codes: $0{ }^{\prime * * * \prime} 0.001^{\prime * *}$ $0.01^{\prime *} 0.05^{\prime} \cdot{ }^{\prime} 0.1^{\prime \prime}{ }^{\prime} 1$ 
Supplementary Table 3 Model selection for large/small fruits in the New World (BiSSE). Eight Binary State Speciation and Extinction (BiSSE) models were fitted to the palm Maximum Clade Credibility (MCC) phylogenetic tree to compare speciation, extinction and transition rates of small- vs. large-fruited New World palm lineages. The best-fitting model given the fewest number of parameters (i.e. 4 Df) is indicated in bold (*). This model indicates that New World small- and large-fruited palm lineages have similar speciation and extinction rates.

\begin{tabular}{|c|c|c|c|c|c|}
\hline Model constraints & Df & LnLik & AIC & ChiSq & $\mathbf{P}$ \\
\hline Full (no constrain) & 6 & -2218.3 & 4448.6 & & \\
\hline$\lambda_{\text {small }} \sim \lambda_{\text {large }}$ & 5 & -2219.1 & 4448.2 & 1.5633 & 0.211 \\
\hline$\mu_{\text {small }} \sim \mu_{\text {large }}$ & 5 & -2218.6 & 4447.2 & 0.5500 & 0.458 \\
\hline 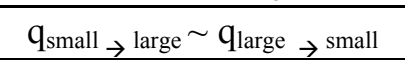 & 5 & -2224.0 & 4458.0 & 11.4470 & $0.0007 * * *$ \\
\hline $\begin{array}{c}* \lambda_{\text {small }} \sim \lambda_{\text {large, }} \mu_{\text {small }} \sim \\
\mu_{\text {large }} \\
\end{array}$ & 4 & -2219.9 & 4447.8 & 3.2443 & 0.197 \\
\hline $\begin{array}{c}\lambda_{\text {small }} \sim \lambda_{\text {large, }}, \mathrm{q}_{\text {small }} \rightarrow \text { large } \\
\mathrm{q}_{\text {large } \rightarrow \text { small }}\end{array}$ & 4 & -2224.6 & 4457.2 & 12.5629 & $0.002 * *$ \\
\hline $\begin{array}{c}\mu_{\text {small }} \sim \mu_{\text {large, }} \mathrm{q}_{\text {small } \rightarrow \text { large }} \sim \\
\mathrm{q}_{\text {large } \rightarrow \text { small }}\end{array}$ & 4 & -2226.7 & 4461.4 & 16.7662 & $0.0002 * * *$ \\
\hline 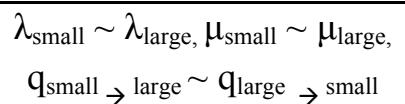 & 3 & -2233.3 & 4472.7 & 30.0633 & $\begin{array}{l}1.3 \mathrm{e}-06 \\
* * *\end{array}$ \\
\hline
\end{tabular}

$\mathrm{Df}=$ degrees of freedom, $\mathrm{LnLik}=\log$ likelihood, $\mathrm{AIC}=$ Akaike Information Criterion, $\mathrm{ChiSq}$ $=$ Chi-square, $\mathrm{P}=$ significance of the model compared to the full model, $\lambda=$ speciation rate, $\mu$ $=$ extinction rate, $\mathrm{q}=$ transition rate, $\sim=$ equal to (constrain). Signif. codes: $0{ }^{\prime * * * \prime} 0.001^{\prime * *}$ $0.01^{\prime *} 0.05^{\prime} \cdot{ }^{\prime} 0.1^{\prime \prime} 1$ 
Supplementary Table 4 Model selection for large/small fruits in the Old World (BiSSE). Eight Binary State Speciation and Extinction (BiSSE) models were fitted to the palm Maximum Clade Credibility (MCC) phylogenetic tree to compare speciation, extinction and transition rates of small- vs. large-fruited Old World palm lineages. The best-fitting model given the fewest number of parameters (i.e. 6 Df) is indicated in bold $(*)$. This model indicates that Old World small- and large-fruited palm lineages have different speciation and extinction rates.

\begin{tabular}{|c|c|c|c|c|c|}
\hline Model constraints & Df & LnLik & AIC & ChiSq & $\mathbf{P}$ \\
\hline * Full (no constrain) & 6 & -3754.9 & 7521.8 & & \\
\hline$\lambda_{\text {small }} \sim \lambda_{\text {large }}$ & 5 & -3780.9 & 7571.7 & 51.903 & $\begin{array}{l}5.8 \mathrm{e}-13 \\
* * *\end{array}$ \\
\hline$\mu_{\text {small }} \sim \mu_{\text {large }}$ & 5 & -3767.8 & 7545.6 & 25.739 & $\begin{array}{l}3.9 \mathrm{e}-07 \\
* * *\end{array}$ \\
\hline $\mathrm{q}_{\text {small } \rightarrow \text { large }} \sim \mathrm{q}_{\text {large } \rightarrow \text { small }}$ & 5 & -3761.9 & 7533.8 & 13.940 & $0.0002 * * *$ \\
\hline$\lambda_{\text {small }} \sim \lambda_{\text {large, }} \mu_{\text {small }} \sim \mu_{\text {large }}$ & 4 & -3822.6 & 7653.2 & 135.351 & $\begin{array}{c}<2.2 \mathrm{e}-16 \\
* * *\end{array}$ \\
\hline $\begin{array}{c}\lambda_{\text {small }} \sim \lambda_{\text {large, }} \mathrm{q}_{\text {small }} \rightarrow \text { large } \\
\mathrm{q}_{\text {large }} \rightarrow \text { small } \\
\end{array}$ & 4 & -3782.1 & 7572.3 & 54.474 & $\begin{array}{c}1.5 \mathrm{e}-12 \\
* * * \\
\end{array}$ \\
\hline $\begin{array}{c}\mu_{\text {small }} \sim \mu_{\text {large, }} \mathrm{q}_{\text {small } \rightarrow \text { large }} \sim \\
\mathrm{q}_{\text {large } \rightarrow \text { small }}\end{array}$ & 4 & -3767.8 & 7543.6 & 25.737 & $\begin{array}{c}2.6 \mathrm{e}-06 \\
* * *\end{array}$ \\
\hline $\begin{array}{c}\lambda_{\text {small }} \sim \lambda_{\text {large, }} \mu_{\text {small }} \sim \mu_{\text {large }} \\
\text { q }_{\text {small } \rightarrow \text { large }} \sim \text { qlarge }_{\rightarrow} \text { small }\end{array}$ & 3 & -3823.0 & 7652.1 & 136.278 & $\begin{array}{c}<2.2 \mathrm{e}-16 \\
* * *\end{array}$ \\
\hline
\end{tabular}

$\mathrm{Df}=$ degrees of freedom, $\mathrm{LnLik}=\log$ likelihood, $\mathrm{AIC}=$ Akaike Information Criterion, $\mathrm{ChiSq}$ $=$ Chi-square, $\mathrm{P}=$ significance of the model compared to the full model, $\lambda=$ speciation rate, $\mu$ $=$ extinction rate, $\mathrm{q}=$ transition rate, $\sim=$ equal to (constrain). Signif. codes: $0{ }^{\prime * * * \prime} 0.001^{\prime * *}$ $0.01^{\prime * \prime} 0.05^{\prime} .{ }^{\prime} 0.1^{\prime \prime} 1$ 
Supplementary Table 5 Model selection after correcting for plant size (BiSSE). Trait-dependent speciation, extinction and transition rate model selection under the Binary State Speciation and Extinction (BiSSE) model for all palms, after correcting for the effect of maximum palm stem height on fruit size. Eight BiSSE models were fitted to the palm Maximum Clade Credibility (MCC) phylogenetic tree. The best-fitting model given the fewest number of parameters is indicated in bold $(*)$. This model indicates that speciation, extinction and transition rates are different between small- and large-fruited palm lineages.

\begin{tabular}{|c|c|c|c|c|c|}
\hline Model constraints & Df & LnLik & AIC & ChiSq & $\mathbf{P}$ \\
\hline *Full (no constrain) & 6 & -5501.5 & 11015 & & \\
\hline$\lambda_{\text {small }} \sim \lambda_{\text {large }}$ & 5 & -5511.1 & 11032 & 19.355 & $\begin{array}{c}1.1 \mathrm{e}-05 \\
* * *\end{array}$ \\
\hline$\mu_{\text {small }} \sim \mu_{\text {large }}$ & 5 & -5506.1 & 11022 & 9.200 & $0.002 * *$ \\
\hline $\mathrm{q}_{\text {small }} \rightarrow$ large $\sim \mathrm{q}_{\text {large }} \rightarrow$ small & 5 & -5532.5 & 11075 & 62.126 & $\begin{array}{l}3.2 \mathrm{e}-15 \\
* * *\end{array}$ \\
\hline$\lambda_{\text {small }} \sim \lambda_{\text {large, }} \mu_{\text {small }} \sim \mu_{\text {large }}$ & 4 & -5525.3 & 11059 & 47.701 & $\begin{array}{l}4.4 \mathrm{e}-11 \\
* * *\end{array}$ \\
\hline $\begin{array}{c}\lambda_{\text {small }} \sim \lambda_{\text {large, }} \mathrm{q}_{\text {small }} \rightarrow \text { large } \\
\mathrm{q}_{\text {large }} \rightarrow \text { small }\end{array}$ & 4 & -5536.1 & 11080 & 69.274 & $\begin{array}{c}8.9 \mathrm{e}-16 \\
* * *\end{array}$ \\
\hline $\begin{array}{c}\mu_{\text {small }} \sim \mu_{\text {large, }}, \mathrm{q}_{\text {small }} \rightarrow \text { large } \\
\mathrm{q}_{\text {large } \rightarrow \text { small }}\end{array}$ & 4 & -5544.7 & 11098 & 86.566 & $\begin{array}{c}<2.2 \mathrm{e}-16 \\
* * *\end{array}$ \\
\hline $\begin{array}{c}\lambda_{\text {small }} \sim \lambda_{\text {large, }} \mu_{\text {small }} \sim \mu_{\text {large }} \\
\mathrm{q}_{\text {small } \rightarrow \text { large }} \sim \mathrm{q}_{\text {large }} \rightarrow \text { small }\end{array}$ & 3 & -5557.4 & 11121 & 111.906 & $\begin{array}{c}<2.2 \mathrm{e}-16 \\
* * *\end{array}$ \\
\hline
\end{tabular}

$\mathrm{Df}=$ degrees of freedom, $\mathrm{LnLik}=\log$ likelihood, $\mathrm{AIC}=$ Akaike Information Criterion, $\mathrm{ChiSq}$

$=$ Chi-square, $\mathrm{P}=$ significance of the model compared to the full model, $\lambda=$ speciation rate, $\mu$

$=$ extinction rate, $\mathrm{q}=$ transition rate, $\sim=$ equal to (constrain). Signif. codes: $0{ }^{\prime * * * \prime} 0.001^{\prime * * \prime}$

$0.01^{\prime * \prime} 0.05^{\prime} . .^{\prime} 0.1^{\prime \prime} 1$ 
Supplementary Table 6 Model selection after correcting for plant size (QuaSSE).

Trait-dependent speciation rate model selection under the Quantitative Speciation and Extinction (QuaSSE) model for all palms, after correcting for the effect of maximum stem height on fruit size. Residuals of $\log$ (fruit length) against $\log$ (maximum stem height) as a continuous trait were tested for their effect on speciation rates on the palm Maximum Clade Credibility (MCC) phylogenetic tree. QuaSSE can be used to test whether the speciation rate follows a constant, a linear or a sigmoidal response curve to (residual) log-transformed fruit length. Values range from -1 to 1 , indicating residual sizes from ca. $0.1 \mathrm{~cm}$ to $10 \mathrm{~cm}$. The best model is indicated in bold (*). This model indicates that speciation rates follow a sigmoidal relationship in response to residual fruit sizes.

\begin{tabular}{|c|c|c|c|c|}
\hline Model & Df & InLik & AIC & $\Delta$ AIC \\
\hline Constant $\boldsymbol{\lambda}$ & 3 & -4582.0 & 9169.9 & 159.9 \\
\hline Linear $\boldsymbol{\lambda}$ & 4 & -4507.6 & 9023.2 & 13.2 \\
\hline Sigmoidal $\boldsymbol{\lambda}$ & 6 & -4500.4 & 9012.8 & 2.8 \\
\hline Linear $\boldsymbol{\lambda}+$ drift & 5 & -4506.8 & 9023.6 & 13.5 \\
\hline${ }^{*}$ Sigmoidal $\boldsymbol{\lambda}+$ drift & $\mathbf{7}$ & $\mathbf{- 4 4 9 8 . 0}$ & $\mathbf{9 0 1 0 . 0}$ & $\mathbf{0}$ \\
\hline
\end{tabular}

Sampling fraction: $1685 / 2539$ species $=0.66, \mathrm{Df}=$ degrees of freedom, $\operatorname{lnLik}=\log$ likelihood, $\mathrm{AIC}=$ Akaike Information Criterion, $\triangle \mathrm{AIC}=$ different in AIC compared to the best model. 


\section{Supplementary Table 7 Models tested in the Multiple State Speciation and Extinction (MuSSE) framework.}

The sixteen models describe the effect of two binary traits on speciation, extinction and transition rates. These models increase in complexity from the base model in which traits do not affect speciation, extinction and transition rates (model 0) to the most complex model in which speciation, extinction and transition rates are affected by additive and interaction effects of the two binary traits (model 15 ). ${ }^{* *} 0$ : no additive or interaction effects; 1 : additive effects; 2: additive and interaction effects on rates.

\begin{tabular}{|c|c|c|c|}
\hline Model & Model description & $\begin{array}{c}\text { Model } \\
\text { parameters } \\
(\boldsymbol{\lambda} \boldsymbol{\mu} \mathbf{q})\end{array}$ & D** \\
\hline 0 & Base model & 000 & 6 \\
\hline 1 & Additive trait effects on $\lambda$ & 100 & 8 \\
\hline 2 & Additive trait effects on $\mu$ & 010 & 8 \\
\hline 3 & Additive and interaction trait effects on $\lambda$ & 200 & 9 \\
\hline 4 & Additive and interaction trait effects on $\mu$ & 020 & 9 \\
\hline 5 & Additive trait effects on q & 001 & 10 \\
\hline 6 & Additive trait effects on $\lambda$ and $\mu$ & 110 & 10 \\
\hline 7 & Additive and interaction trait effects on $\lambda$, additive effect on $\mu$ & 210 & 11 \\
\hline 8 & Additive and interaction trait effects on $\mu$, additive effect on $\lambda$ & 120 & 11 \\
\hline 9 & Additive trait effects on $\lambda$ and $\mathrm{q}$ & 101 & 12 \\
\hline 10 & Additive trait effects on $\mu$ and $\mathrm{q}$ & 011 & 12 \\
\hline 11 & Additive and interaction trait effects on $\lambda$ and $\mu$ & 220 & 12 \\
\hline 12 & Additive trait effects on $\lambda, \mu$ and $\mathrm{q}$ & 111 \\
\hline 13 & Additive and interaction trait effects on $\lambda$, additive effects on $\mu$ & 211 & 15 \\
\hline 14 & and q & 121 & 15 \\
\hline 15 & Additive and interaction trait effects on $\mu$, additive effects on $\lambda$ & 221 & 16 \\
\hline
\end{tabular}

$\mathrm{Df}=$ degrees of freedom, $\lambda=$ speciation rate, $\mu=$ extinction rate, $\mathrm{q}=$ transition rate. 
Supplementary Table 8 Model selection for fruit size and understory habitat (MuSSE). Sixteen Multiple State Speciation and Extinction (MuSSE) models were fitted to the palm Maximum Clade Credibility (MCC) phylogenetic tree for global, New World and Old World palms. These models include the additive and interaction effects of small fruits and understory habitat on speciation, extinction and transition rates, as compared to large-fruited canopy palms (the base model). The best-fitting model given the fewest number of parameters is indicated in bold $(*)$. As a stepwise model selection approach was applied, not all models were tested for each dataset. For details on the models see Supplementary Table 7. **0: no additive or interaction effects; 1 : additive effects; 2 : additive and interaction effects on rates.

\begin{tabular}{|c|c|c|c|}
\hline Model & Model parameters $(\lambda \mu \mathrm{q})^{* *}$ & Df & AIC \\
\hline \multicolumn{4}{|c|}{ Global } \\
\hline 0 & 000 & 6 & 15730 \\
\hline 1 & 100 & 8 & 15528 \\
\hline 2 & 010 & 8 & 15549 \\
\hline 5 & 001 & 10 & 15715 \\
\hline 6 & 110 & 10 & 15518 \\
\hline 7 & 111 & 14 & 15504 \\
\hline $13 *$ & 211 & 15 & 15491 \\
\hline 14 & 121 & 15 & 15506 \\
\hline \multicolumn{4}{|c|}{ New World } \\
\hline 0 & 000 & 6 & 5686.9 \\
\hline 1 & 100 & 8 & 5590.3 \\
\hline 2 & 010 & 8 & 5582.2 \\
\hline 5 & 001 & 10 & 5655.2 \\
\hline 6 & 110 & 10 & 5588.4 \\
\hline 12 & 111 & 14 & 5561.3 \\
\hline $13 *$ & 211 & 15 & 5545.4 \\
\hline 14 & 121 & 15 & 5552.5 \\
\hline 15 & 221 & 16 & 5546.3 \\
\hline \multicolumn{4}{|c|}{ Old World } \\
\hline 0 & 000 & 6 & 10094.2 \\
\hline 1 & 100 & 8 & 9916 \\
\hline 2 & 010 & 8 & 9935.9 \\
\hline 5 & 001 & 10 & 10093 \\
\hline 6* & 110 & 10 & 9899.2 \\
\hline 7 & 210 & 11 & 10104.2 \\
\hline 8 & 120 & 11 & 10105 \\
\hline 12 & 111 & 14 & 9903.1 \\
\hline
\end{tabular}

$\mathrm{Df}=$ degrees of freedom, $\mathrm{AIC}=$ Akaike Information Criterion, $\lambda=$ speciation rate, $\mu=$ extinction rate, $\mathrm{q}=$ transition rate. 
Supplementary Table 9 Model selection for fruit size and island colonization (MuSSE).

Sixteen Multiple State Speciation and Extinction (MuSSE) models were fitted to the palm Maximum Clade Credibility (MCC) phylogenetic tree for global, New World and Old World palms. These models include the additive and interaction effects of small fruits and oceanic island distributions on speciation, extinction and transition rates, as compared to large-fruited mainland or continental island-distributed palms (the base model). The best-fitting model given the fewest number of parameters is indicated in bold (*). As a stepwise model selection approach was applied, not all models were tested for each dataset. For details on the models see Supplementary Table 7. $* * 0$ : no additive or interaction effects; 1 : additive effects; 2 : additive and interaction effects on rates.

\begin{tabular}{|c|c|c|c|}
\hline Model & Model parameters $(\lambda \mu \mathrm{q})^{* *}$ & Df & AIC \\
\hline \multicolumn{4}{|c|}{ Global } \\
\hline 0 & 000 & 6 & 13757 \\
\hline 1 & 100 & 8 & 13668 \\
\hline 2 & 010 & 8 & 13661 \\
\hline 5 & 001 & 10 & 13746 \\
\hline 6 & 110 & 10 & 13656 \\
\hline 12 & 111 & 14 & 13658 \\
\hline 7* & 210 & 11 & 13647 \\
\hline 8 & 120 & 11 & 13653 \\
\hline 11 & 220 & 12 & 13651 \\
\hline \multicolumn{4}{|c|}{ New World } \\
\hline 0 & 0 & 6 & 4670.4 \\
\hline $1 *$ & 100 & 8 & 4659.4 \\
\hline $2 *$ & 010 & 8 & 4658.9 \\
\hline 3 & 200 & 9 & 4660.4 \\
\hline 4 & 020 & 9 & 4658.9 \\
\hline 5 & 001 & 10 & 4665.4 \\
\hline 6 & 110 & 10 & 4661.1 \\
\hline 9 & 101 & 12 & 4661 \\
\hline 10 & 011 & 12 & 4659 \\
\hline \multicolumn{4}{|c|}{ Old World } \\
\hline 0 & 0 & 6 & 8998.3 \\
\hline 1 & 100 & 8 & 8867.1 \\
\hline 2 & 010 & 8 & 8905.2 \\
\hline 5 & 001 & 10 & 8996 \\
\hline 6 & 110 & 10 & 8857.9 \\
\hline 12 & 111 & 14 & 8852.4 \\
\hline $13 *$ & 211 & 15 & 8832.5 \\
\hline 14 & 121 & 15 & 8839.5 \\
\hline 15 & 221 & 16 & 8834.5 \\
\hline
\end{tabular}

$\mathrm{Df}=$ degrees of freedom, AIC $=$ Akaike Information Criterion, $\lambda=$ speciation rate, $\mu=$ extinction rate, $\mathrm{q}=$ transition rate. 


\section{Supplementary Figures}

Supplementary Figure 1 | Correlation between fruit size and plant size in palms. The figure shows the relationship between $\log$ (fruit size) $(\mathrm{cm})$ and $\log$ (maximum stem height), with larger palms having on average larger fruits. The smoothed line was generated in the ggplot R package. The grey box indicates the confidence interval around the smoothed line.

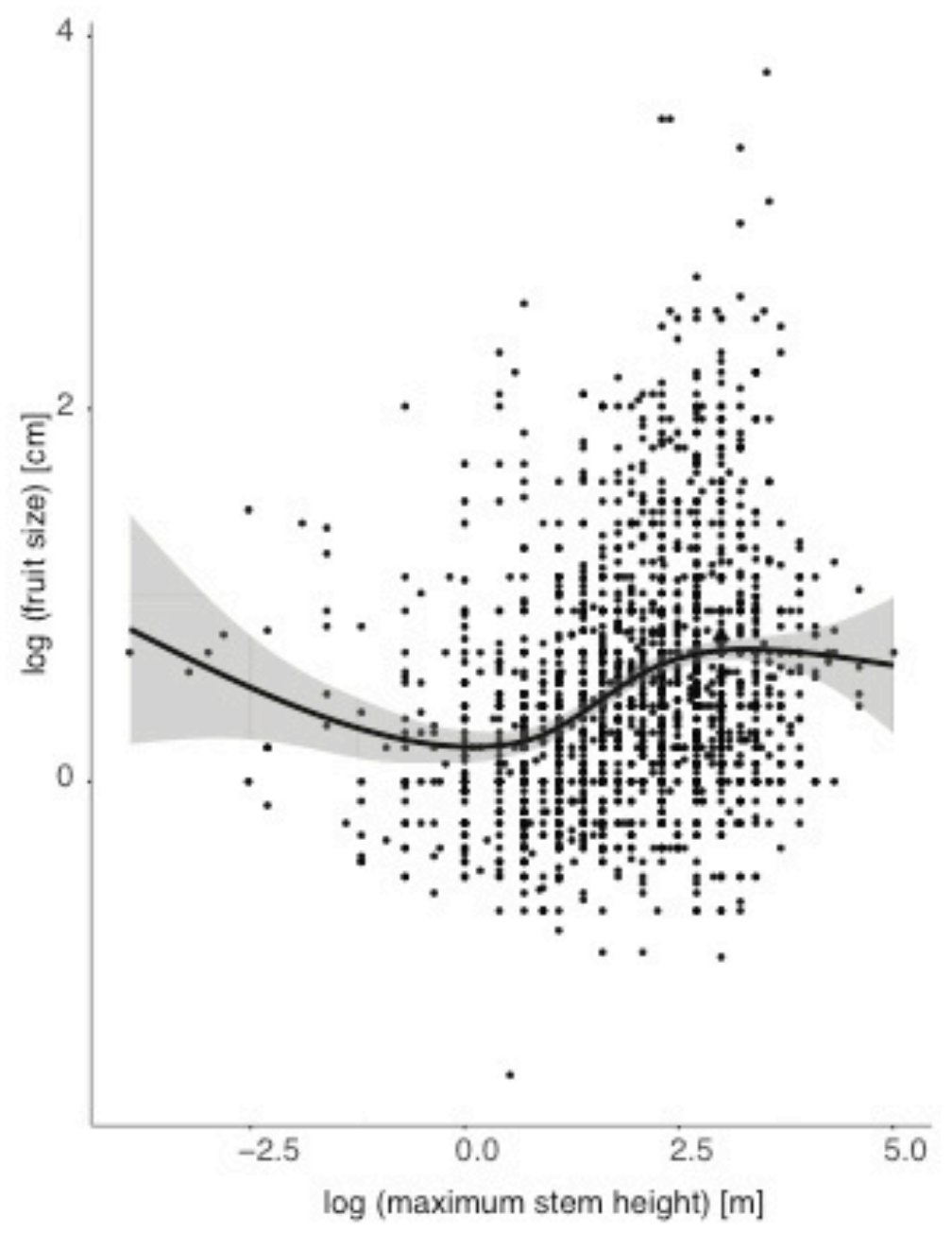




\section{Supplementary Figure 2 | Fruit size frequency distributions of palms.}

Fruit size frequencies for small- and large-fruited palms, indicated for all palms, understory, canopy, island-distributed and mainland- or continental island- distributed palm species.

Understory palms generally have smaller fruits than canopy palms, both for the small fruit $(<$ $4 \mathrm{~cm})$ and large fruit $(\geq 4 \mathrm{~cm})$ groups. Mainland palms generally have slightly smaller fruits than island-distributed palms, but only for the small fruit $(<4 \mathrm{~cm})$ group. $m=$ median, $n=$ sample size.

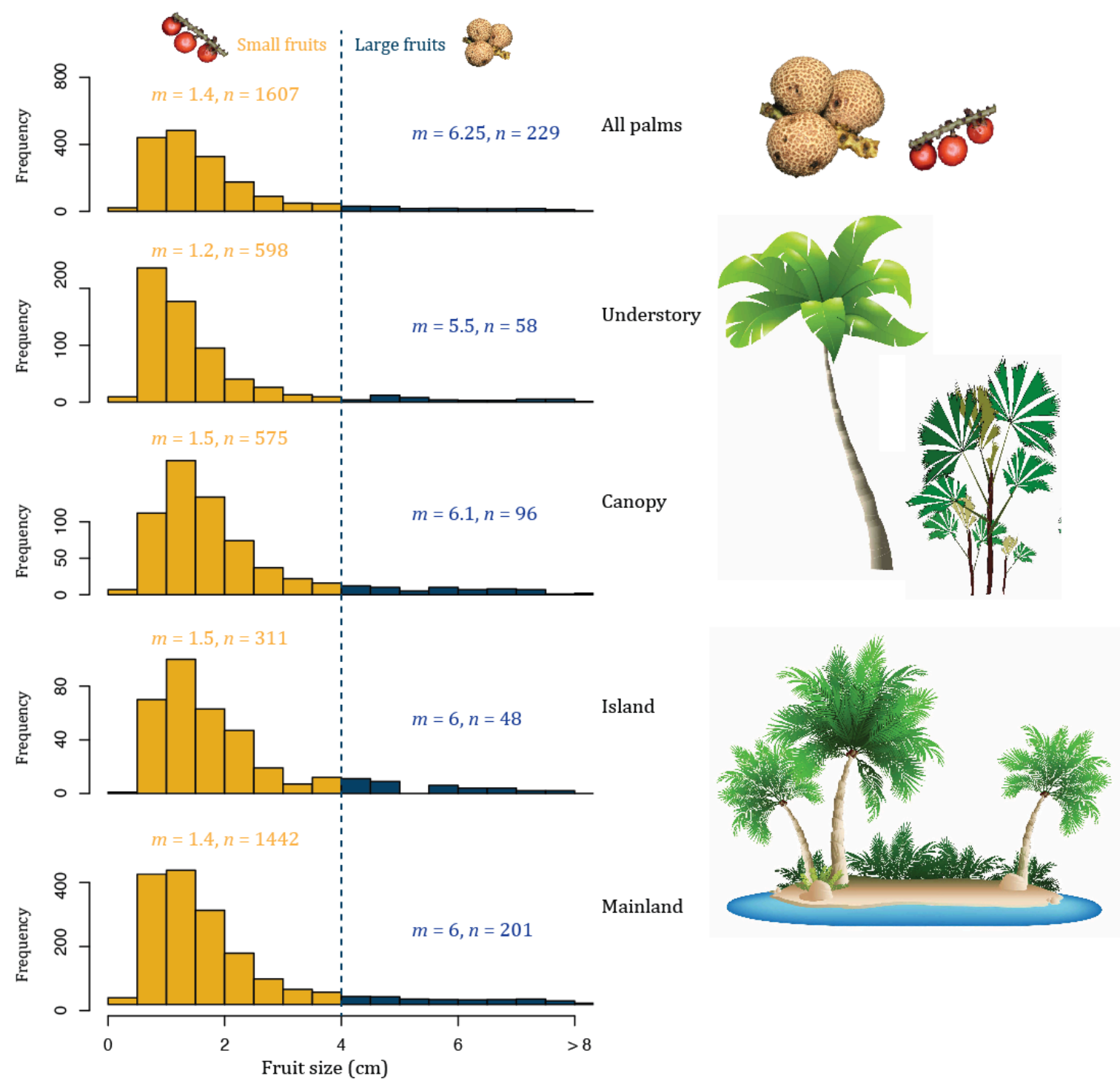




\section{Supplementary Figure 3 | Diversification rates under simulated binary traits (BiSSE).}

Bayesian posterior densities resulting from the Binary State Speciation and Extinction

(BiSSE) model for speciation (lambda), extinction (mu), transition (q), and net diversification

(r) rates. These rates were estimated by Bayesian Markov Chain Monte Carlo methods for 10,000 generations for palm lineages after simulating binary traits on 100 randomly sampled, empirical palm phylogenetic trees. These binary traits were simulated under different transition rate scenarios. As $95 \%$ posterior densities between trait states (indicated with 0 and 1 on the $\mathrm{x}$-axes) within each scenario strongly overlap (compare same colored box-andwhiskers in each plot), we can reject the hypothesis that the distribution of branch lengths in our empirical data causes our observed results (compare to Fig. 2 and Supplementary Fig. 4).
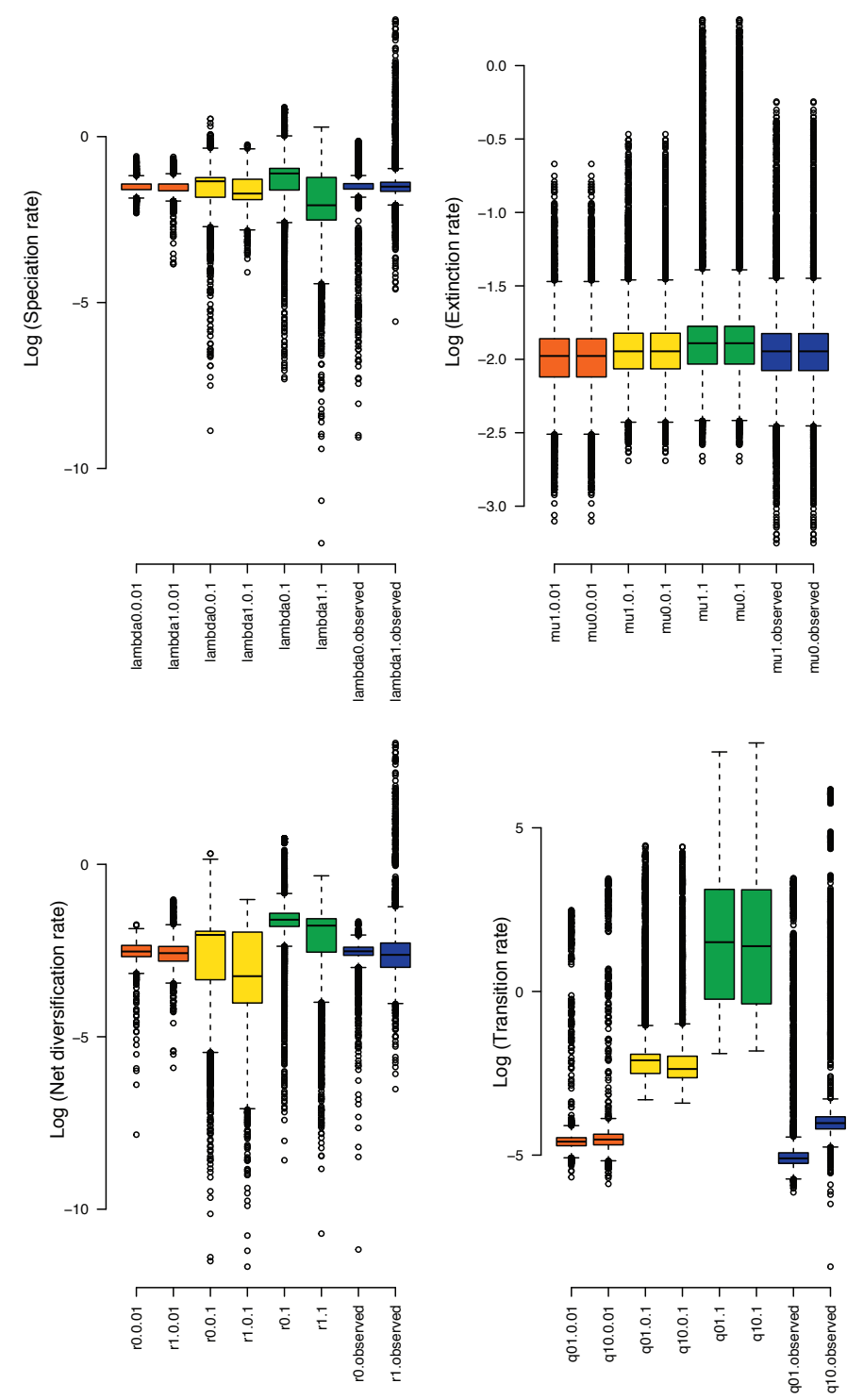

Transition rate used for neutral trait evolution:

$\square 0.01$

$\square 0.1$

$\square 1$

observed (emperical): $q$ large to small fruits $=0.017$; q small to large fruits $=0.006$ 


\section{Supplementary Figure 4 | Diversification rates of small- and large-fruited palms (BiSSE).}

Bayesian posterior densities resulting from the Binary State Speciation and Extinction model (BiSSE) of speciation (lambda), extinction (mu), transition (q) and net diversification (r) rates as estimated by Bayesian Markov Chain Monte Carlo methods on 100 randomly sampled palm phylogenetic trees for 10,000 generations, for global, New World (NW), Old World (OW) and residual fruit size (after correcting for maximum stem height) small and largefruited palm lineages. ' 0 ' refers to small-fruited palm lineages, ' 1 ' to large-fruited palm lineages, $\mathrm{NW}=$ New World, OW = Old World.
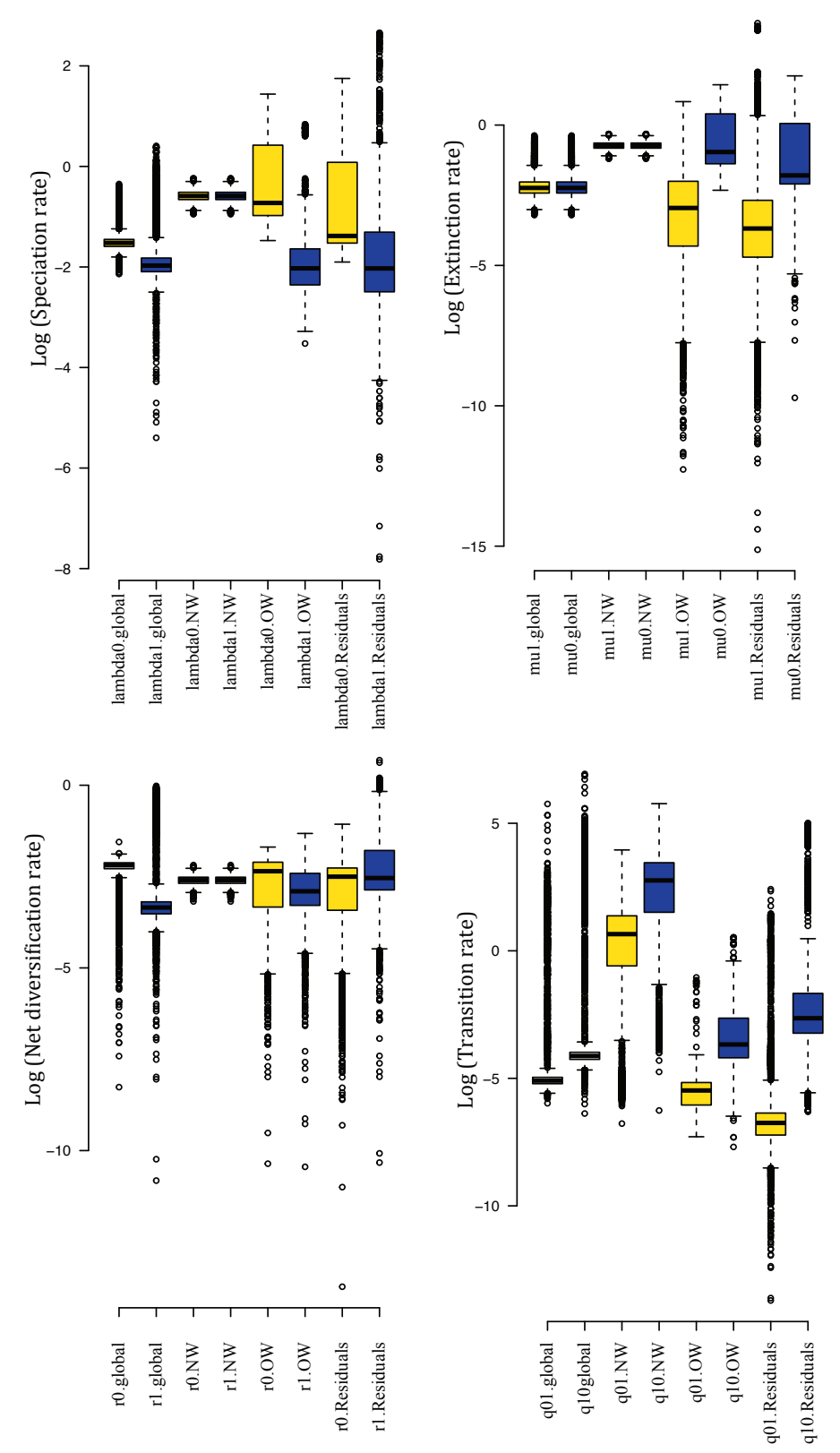
Supplementary Figure 5 | Speciation rate in response to fruit size (QuaSSE).

The effect of palm residual fruit size $(\mathrm{cm})$ on speciation rates under the best-fitting Quantitative Speciation and Extinction (QuaSSE) model (sigmoidal + drift, Supplementary Table 6). This indicates that palms with large fruit sizes have lower rates of speciation than palms with small fruit sizes, following a sigmoidal relationship.

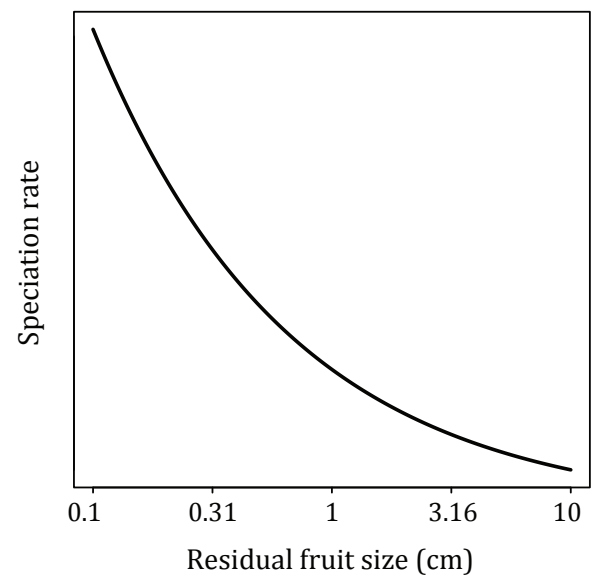


Supplementary Figure 6 | Phylorate plot of speciation rates in palms (BAMM).

Phylorate plot showing speciation rates as estimated from Bayesian Analysis of Macroevolutionary Mixtures (BAMM) on the palm Maximum Clade Credibility (MCC) phylogenetic tree. The speciation rates at the tips of the phylogenetic tree (i.e. the species) were regressed against fruit sizes of palms and compared to 1000 permutations. These results indicated that a significant negative relationship between fruit size and speciation rates exists in palms (i.e. palms with larger fruits have on average lower speciation rates than palms with smaller fruits).

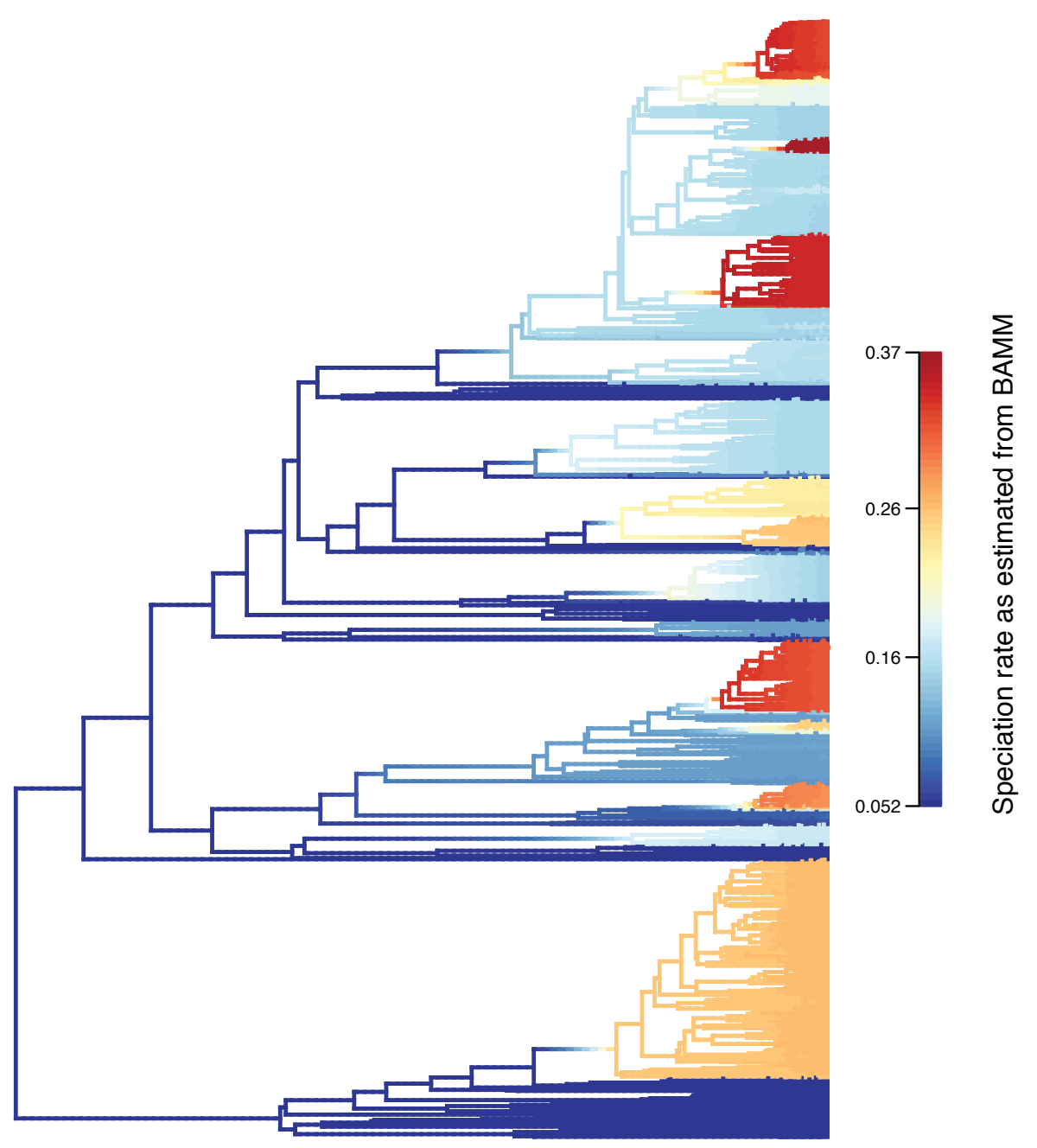


Supplementary Figure 7 | Trait interaction effects on diversification rates (MuSSE). Bayesian posterior densities resulting from the Multiple State Speciation and Extinction (MuSSE) model for extinction, transition and net diversification rates. These rates were estimated by Bayesian Markov Chain Monte Carlo methods on 100 randomly sampled palm phylogenetic trees for 10,000 generations, for global, New World (NW) and Old World (OW) palms. (a) Rates as estimated for small-fruited palm lineages in the understory, compared to a base model of large-fruited canopy palm lineages. (b) Rates as estimated for small-fruited palm lineages distributed on oceanic islands, compared to a base model of large-fruited mainland- or continental island-distributed palm lineages.
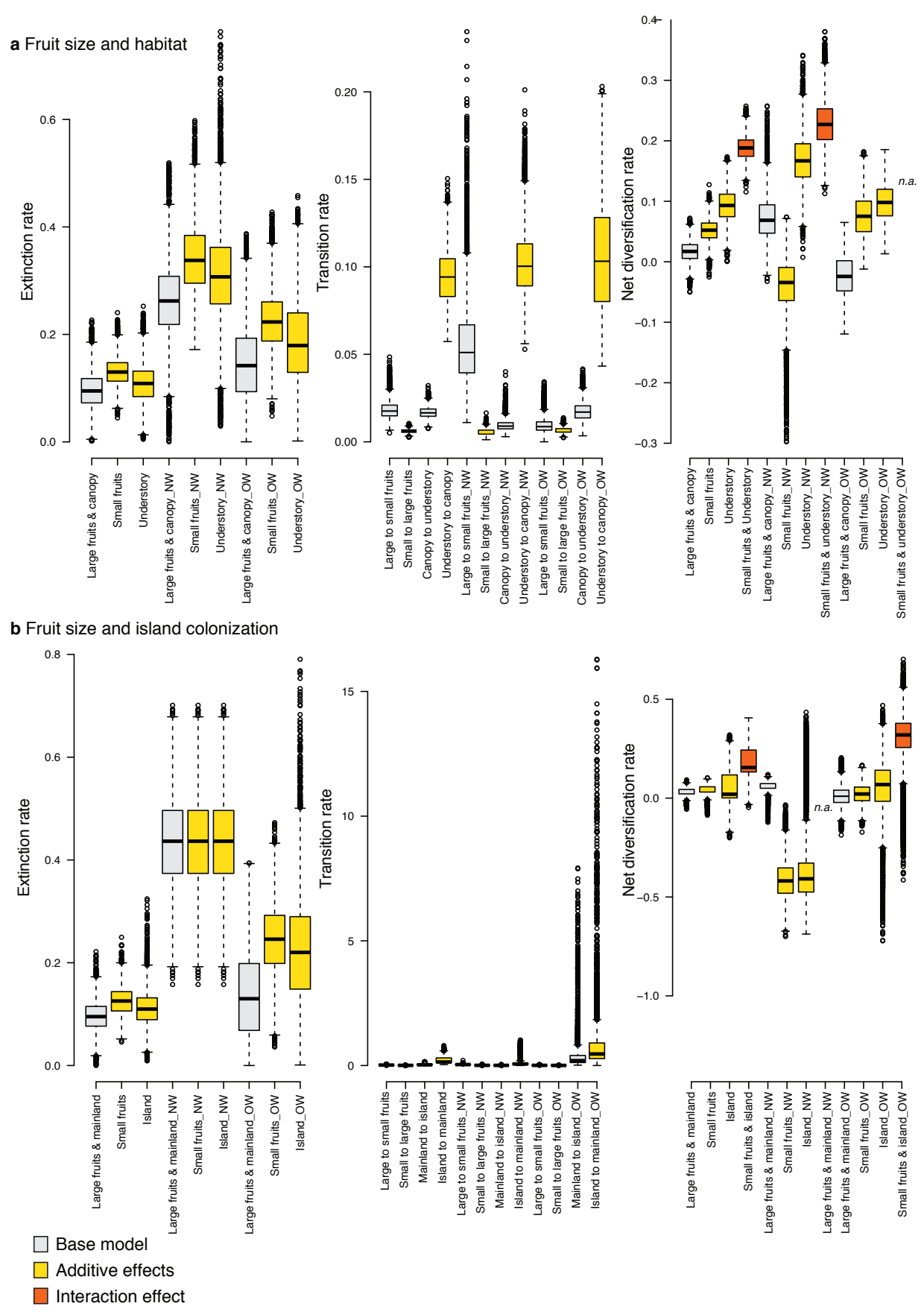


\section{Supplementary data sources}

Trait data sources used to obtain fruit sizes and maximum stem heights of palms, as used in this study.

\section{Herbaria:}

Aarhus University Herbarium

Kew Royal Botanic Gardens Herbarium

\section{Palm websites:}

Palmweb (www.palmweb.org)

Palmpedia (www.palmpedia.net)

\section{Literature:}

Bacon, C. D. \& Baker, W. J. (2011): Saribus resurrected. Palms 55: 109-116.

Barfod, A. S. (1991): A monographic study of the subfamily Phytelephantoideae (Arecaceae). Opera Botanica 105: 1-73

Barrow S. C. (1998): A monograph of Phoenix L. (Palmae: Coryphoideae). Kew Bulletin 53: 513-575

Bergmann, Birgitte (pers. comm.)

Bernal, R., Galeano, G. \& Hodel, D.R. (2004): A new speciesd of Chamaedorea from Columbia. Palms 48: 27-29.

Blicher-Mathiesen, U. Unpubl.: The subtribe Attaleinae (Palmae) in Ecuador

Borchsenius, F. \& Bernal, R. (1996): Aiphanes (Palmae). Flora Neotropica 70: 1-94

Borchsenius, F., Pedersen, H. B. \& Balslev, H. (1998): Manual to the palms of Ecuador. AAU Reports 37, Aarhus University Press, Aarhus.

Cascante, A. (2000): Additions to the Genus Batcris (Arecaceae) of Mesoamerica. Palms 44: 146-153. de Guzman, E. D. \& Fernando, E. S. (1986): Guide to Philippine flora and fauna. Natural Resources Management Center, Ministry of Natural Resources: University of the Philippines.

Dowe J. L. \& Hodel D. R. (1994): A revision of Archontophoenix H.Wendl. \& Drude (Arecaceae). Austrobaileya 4: 227-44.

Dowe, J.L. \& Ferrero, M.D. (2000): A new species of rheophytic palm from New Guinea. Palms 44: 194-197.

Dowe, J. L. \& Ferrero, M. D. (2001): Revision of Calyptrocalyx and the New Guinea species of Linospadix (Linospadicinae: Arecoideae: Arecaceae). Blumea 46: 207-251.

Dowe, J. L. (2010): Australian palms: biogeography, ecology and systematics. CSIRO Publishing, Collingwood, Australia.

Dowe, J. L. \& Irvine, A. K. (1997): A revision of Linospadix in Australia, with the description of a new species. Principes 41: 192-197, 211-217.

Dransfield (1979): A manual of the rattans of the Malay Peninsula. Malayan Forest Records 29.

Dransfield, J. (1972a): The genus Borassodendron in Malesia. Reinwardtia 8: 351-363.

Dransfield, J. (1972b): The genus Johannesteijsmannia H.E. Moore Jr. Gard Bull. Singapore 26: 63-83. 
Dransfield, J. (1978b): The growth forms of rain forest palms. Pages 247-268 in Tomlinson, P.B. and M.H. Zimmermann (eds). Tropical trees as living systems. Cambridge University Press. New York.

Dransfield, J. (1986): Palmae. In: Flora of tropical East Africa (ed. Polhill, R. M.), Balkema, Rotterdam.

Dransfield, J. \& Beentje, H. (1995): Palms of Madagascar. Royal Botanical Gardens, Kew.

Dransfield, J. (1984): The rattans of Sabah. Sabah forest record 13 (1984).

Dransfield, J., Uhl, N. W., Asmussen, C. B., Baker, W. J., Harley, M. M. \& Lewis, C. E. (2008):

Genera Palmarum - the evolution and classification of palms. Royal Botanic Gardens, Kew, London.

Essig F. B. (1978): A revision of the genus Ptychosperma Labill. (Arecaceae). Allertonia 1: 415-78.

Essig, F. B. \& Hernandez, N. (2002) A systematic histological study of palm fruits. V. Subtribe Archontophoenicinae (Arecaceae). Brittonia, 54, 65-71.

Essig, F. B. \& Litten, L. (2004) A systematic histological analysis of palm fruits VII. The Cyrtostachydinae (Arecaceae). Brittonia, 56, 375-379.

Essig, F. B. (2002) A systematic histological study of palm fruits. VI. Subtribe Linospadicinae (Arecaceae). Brittonia, 54, 196-201.

Essig, F. B. (2008) A systematic histological study of palm fruits. VIII. Subtribe Dypsidinae (Arecaceae). Brittonia, 60, 82-92.

Essig, F. B., Bussard, L. \& Hernandez, N. (2001) A systematic histological study of palm fruits. IV. Subtribe Oncospermatinae (Arecaceae). Brittonia, 53, 466-471.

Essig, F. B., Manka, T. J. \& Bussard, L. (1999) A systematic histological study of palm fruits. III. Subtribe Iguanurinae (Arecaceae). Brittonia, 51, 307-325.

Evans (2001): The Indochinese rattan Calamus acanthophyllus: a fire-loving palm. Palms 45. (1): 2528.

Fernando, E. S. (1983): A revision of the genus Nenga. Principes 27: 55-70.

Fong, F. (1986): Studies on the population structure, growth dynamics and resource importance of nipa palm (Nypa fruticans Wurmb.). Ph.D. diss., University of Malaya.

Galeano, G. \& Bernal, R. (2010): Palmas de Colombia: guia de campo. Panamericana Formas e Impresos S.A., Bogota.

Gibbons, M. \& Spanner, T. W. (1996): Medemia argun lives! Principes 40: 65-74.

Glassman S.F. 1987: Revisions of the palm genus Syagrus Mart. And other selected genera in the Cocos alliance. Illinois Biological Monographs 59: 1-414.

Grayum, M.H. (1998 publ. 1999): Nomenclatural and taxonomic notes on Costa Rican palms (Arecaceae), with five new species. Phytologia 84: 307-327.

Hahn, W. (1993): Biosystematics and evolution of the genus Caryota (Palmae: Arecoideae). PhD Thesis, University of Wisconsin, Madison, Wisconsin.

Henderson A. (2002) Evolution and ecology of palms. The New York Botanical Garden Press, Bronx.

Henderson (2007): A revision of Wallichia (Palmae). Taiwania 52: 1-11.

Henderson A. (2009): Palms of Southern Asia. Princeton University Press, Princeton.

Henderson A. (2011): A revision of Geonoma (Arecaceae). Phytotaxa 17: 1-271.

Henderson A., Galeano G. \& Bernal R. (1995): Field guide to the palms of the Americas. Princeton University Press, Princeton, NJ. 
Henderson, A. (1990): Arecaceae part I. Introduction and the Iriarteinae. Flora Neotropica 53: 1-101.

Henderson, A. (2000): Bactris (Palmae). Flora Neotropica Monograph 79: 1-181.

Henderson, A. (2005): A multivariate study of Calyptrogyne (Palmae). Systematic Botany 30: 60-83.

Henderson A. J. \& Bacon C. D. (2011): Lanonia (Arecaceae: Palmae), a new genus from Asia, with a revision of the species. Systematic Botany 36: 883-95.

Hodel, D. R. (1992a): Chamaedorea palms. The International Palm Society, Allen Press, Lawrence, Kansas.

Hodel, D. R. (1992b): Additons to Chamaedorea palms: new species from Mexico and Guatemala and miscellaneous notes. Principes 36: 188-202.

Hodel, D. R. (1995): Three new species of Chamaedorea from Panama. Principes 39: 14-20.

Hodel, D. R. (1996): Two new species of Chamaedorea from Costa Rica. Principes 40: 212-216.

Hodel, D. R. (1997): Two new species of Chamaedorea (Arecaceae). Novon 7: 35-37.

Hodel, D. R. (1998): The palms of Thailand. Allen Press, Lawrence, Kansas.

Hodel, D. R. (2007): A review of the genus Pritchardia. Palms 51: S1-S52.

Hodel, D. R., Herrera, G. \& Cascante, A. (1997): A remarkable new species and additional novelties of Chamaedorea from Costa Rica and Panama. Palm Journal 137: 32-44.

Hodel, D. R., Mont, J. J. C. \& Zuniga, R. (1995): Two new species of Chamaedorea from Honduras. Principes 39: 183-189.

Hodel, D. R. \& Pintaud, J.-C. (1998): The palms of New Caledonia. Pattaya, Thailand: Kampon Tansacha, Nong Nooch Tropical Garden.

Jones, D. L. (1995): Palms throughout the world. Smithsonian Institution Press, Washington, D.C.

Keat, L.C. (1998): Notes on recent palm species and records from Peninsular Thailand. Principes 42: 110-119.

Kiew, R. 1977. Taxonomy, ecology and biology of sago palms in Malaysia and Sarawak. In Sago-76. Proc. 1st International Sago Symposium, Kuching, Malaysia 5-7 July 1976 (K. Tan, ed.), pp. 147-154.

Lorenzi, H. (2010): Brazilian Flora Arecaceae (Palms). Nova Odessa, Instituto Plantarum.

Mogea, J. P. (1991): Indonesia: palm utilization and conservation. In: D. Johnson (ed.), Palms for human needs in Asia, A.A. Balkema, Rotterdam, pp. 37-73.

Moore, H. E. \& Guého, L. J. (1984): Palmiers. In: Bosser, J., Cadet, T., Guého, J. \& Marais, W. (Eds.). Flore des Mascareignes. Famille 189. The Sugar Industry Research Institute, Mauritius, l'Office de la Recherche Scientifique Outre-Mer, Paris, France \& Royal Botanic Gardens, Kew, Richmond, United Kingdom. 34 pp.

Mónica M. R. \& Henderson A. (1990): The genus parajubaea (Palmae). Brittonia 42: 92-9.

Rauwerdink (1986): Rauwerdink, Jan B. "An essay on Metroxylon, the sago palm." Principes (USA) (1986).

Read, R. \& Hodel, D. R. (1990): Arecaceae. Palm Family. In: W. L. Wagner, D. R. Herbst, and S. H. Sohmer (eds.), Manual of the Flowering Plants of Hawai'i. Bishop Museum Special Publication 83. B.P. Bishop Museum, HI, pp. 1360-1375.

Rodd, A. N. (1998): Revision of Livistona (Arecaceae) in Australia. Telopea 8: 49-153.

Russell, T. A. (1968): Palmae. In: Flora of west tropical Africa (ed. Hepper, F.N.), 2nd ed. Whitefriars Press, London. 
Saw, L. G., Dransfield, J. and Keith-Lucas, D. M. (2003): Morphological diversity of the genus Licuala (Palmae). Telopea 10: 187-206

Schönfeldter R., unpubl.

Skov (1994): Geonoma polyandra (Arecaceae), a new species from Ecuador. Nordic journal of botany 14.1: 39-41.

Skov, F. (1989): HyperTaxonomy - a new tool for revisional work and a revision of Geonoma (Palmae) in Ecuador, unpublished

Skov and Balslev (1989): Skov, Flemming, and Henrik Balslev. "A revision of Hyospathe (Arecaceae)." Nordic journal of botany 9.2 (1989): 189-202.

Stauffer F. W., Asmussen C. B., Henderson A. \& Endress P. K. (2003): A revision of Asterogyne (Arecaceae: Arecoideae: Geonomeae). Brittonia 55: 326-56.

Sunderland (2007): Sunderland, Terry CH. Field guide to the rattans of Africa. Royal Botanic Gardens, 2007.

Tuley, P. (1995): The palms of Africa. The Trendrine Press, Zennor.

Zona, S. (1990): A monograph of Sabal (Arecaceae: Coryphoideae). Aliso 12: 583-666. 


\section{Supplementary references}

1 FitzJohn, R. G. Quantitative Traits and Diversification. Systematic Biology 59, 619-633, doi:10.1093/sysbio/syq053 (2010).

2 Rabosky, D. L. \& Goldberg, E. E. Model inadequacy and mistaken inferences of traitdependent speciation. Systematic Biology 64, 340-355, doi:10.1093/sysbio/syu131 (2015).

3 Lewis, P. O. A likelihood approach to estimating phylogeny from discrete morphological character data. Systematic Biology 50, 913-925 (2001).

4 Gamisch, A. Notes on the Statistical Power of the Binary State Speciation and Extinction (BiSSE) Model. Evolutionary Bioinformatics Online 12, 165-174, doi:10.4137/EBO.S39732 (2016).

5 Davis, M. P., Midford, P. E. \& Maddison, W. Exploring power and parameter estimation of the BiSSE method for analyzing species diversification. BMC Evolutionary Biology 13, 1-11, doi:10.1186/1471-2148-13-38 (2013).

6 Maddison, W. P. \& FitzJohn, R. G. The unsolved challenge to phylogenetic correlation tests for categorical characters. Systematic Biology 64, 127-136, doi:10.1093/sysbio/syu070 (2015).

7 Rabosky, D. L. Automatic Detection of Key Innovations, Rate Shifts, and DiversityDependence on Phylogenetic Trees. PLOS ONE 9, e89543, doi:10.1371/journal.pone.0089543 (2014).

8 Faurby, S., Eiserhardt, W. L., Baker, W. J. \& Svenning, J.-C. An all-evidence species-level supertree for the palms (Arecaceae). Molecular Phylogenetics and Evolution 100, 57-69, doi:http://dx.doi.org/10.1016/j.ympev.2016.03.002 (2016).

9 Rabosky, D. L. et al. BAMMtools: an R package for the analysis of evolutionary dynamics on phylogenetic trees. Methods in Ecology and Evolution 5, 701-707, doi:10.1111/2041210X.12199 (2014).

10 Rabosky, D. L. \& Huang, H. A robust semi-parametric test for detecting trait-dependent diversification. Systematic Biology 65, 181-193, doi:10.1093/sysbio/syv066 (2016).

11 Couvreur, T. L. P. et al. Global diversification of a tropical plant growth form: environmental correlates and historical contingencies in climbing palms. Frontiers in Genetics 5, 452 , doi:10.3389/fgene.2014.00452 (2014).

12 FitzJohn, R. G. Diversitree: comparative phylogenetic analyses of diversification in R. Methods in Ecology and Evolution 3, 1084-1092, doi:10.1111/j.2041-210X.2012.00234.X (2012). 